\title{
DUKE-ELDER LECTURE
}

\section{Prevention and Perspective in Retinal Detachment}

\author{
JOHN D. SCOTT \\ Cambridge
}

Mr President, it is a very great honour for me to be invited to deliver the fifth Duke-Elder Lecture. I know that this was the wish of our late and much missed friend Brian Harcourt when he was President of the Ophthalmological Society of the United Kingdom.

Sir Stewart Duke-Elder was a legend in his lifetime. Renowned internationally for his encyclopaedic knowledge and prodigious writings, particularly the Textbook of Ophthalmology, the first volume of which was published in 1932. This great work was an essential source of reference for almost every contribution to the ophthalmic literature for many years, and for those of my generation preparing for examinations the only source of collective clinical information.

Whilst much of what he wrote has been augmented by normal scientific progress, the System of Ophthalmology remains a significant source of historical information for any of us interested in the foundations of our speciality. Volume one, The Eye in Evolution, will remain one of the most fascinating ophthalmology books ever written. Sir Stewart was a highly experienced research scientist; in 1948 he founded the Institute of Ophthalmology and continued as its director until 1965 , and it is largely the result of his personal efforts that it became the main focus for research in ophthalmology in Great Britain in the 1950s and 1960s.

In 1945 he inaugurated the Faculty of Ophthalmology at the Royal College of Surgeons, now of course part of the foundation of our new college.
To relate all Duke-Elder's outstanding contributions to ophthalmology would take all of this hour and more, so that I am very aware of the singular privilege it is to be invited to give this lecture in honour of his memory.

\section{Introduction}

There would be few who would disagree that retinal detachment is a potential disaster for the eye; normal vision is rarely regained and the possibility of permanent disfigurement is significant. From this there follows a strong argument in favour of prevention as an alternative to attempted cure; however the identification of risk and the provision of effective preventive treatment without significant complication remains a fundamental problem.

Traditional teaching in prevention recognises the role of the retinal break in the causation of retinal detachment, and the significance of some predisposing lesions in the pathogenesis of the break. From the time of Gonin and until quite recently it was believed that any retinal degeneration or break was likely to lead to retinal detachment and was treated prophylactically.

Nowadays we have come to realise that not all retinal breaks or degradation need to be treated in this way since we know that these changes are present in about 5\% of the population at large. ${ }^{1,2}$ Prospective studies have demonstrated that where such lesions are discovered by chance the risk of detachment is negligible. ${ }^{3}$ 


\section{Low Risk Cases}

A significant risk factor is introduced if one eye has already developed a detachment and a retinal break is found by chance in the fellow eye; even if this break is asymptomatic there appears to be about a $10 \%$ risk that it will progress. $^{4}$

\section{Symptoms}

The importance of symptoms was emphasised by one study which found that if a retinal tear in the first eye caused even minor vitreous haemorrhage with a reduction in vision, floaters or flashing lights, it was very likely to progress to a detachment. ${ }^{5}$

A study carried out in my department has looked at the significance of symptoms in a different way. ${ }^{6}$ Fifty patients were asked about their symptoms prior to the diagnosis of retinal detachment.

Only $6 \%$ had a flashing light as a first symptom. Fourteen per cent had no symptoms before loss of sight. Twenty-four per cent had a sudden attack of floaters and $29 \%$ first saw a shadow; the other $27 \%$ saw either a blur or scintillations, and these were quite distinct from the peripheral single flash of light.

By direct questioning a flashing light was only noticed in $10 \%$ of patients and was never seen as an isolated symptom.

A flashing light in the peripheral vision occurs in between one quarter and one half of cases presenting with acute symptomatic vitreous detachment; $;^{7}$ about one in eight patients with acute vitreous detachment develop retinal breaks and these are not particularly related to a symptom of flashing light.

It may be concluded then that this symptom is related only to recent vitreous detachment and not to retinal tearing and is significant of risk only if combined with a sudden attack of floaters.

From our patients only one third had symptoms which might have led to an early diagnosis of vitreous detachment complicated by a retinal break and which might have allowed early preventive treatment. The majority presented with symptoms related to the retinal detachment itself, so that early treatment might only have prevented involvement of the macula.

\section{Lattice degeneration}

Where a retinal lesion such as lattice degeneration is concerned we know that the risk of progress to retinal detachment is extremely small. ${ }^{3}$ Even if it is extensive or there are round atrophic holes within the degeneration the risk is only about $0.5 \%$ and in a non-fellow eye would not merit preventive treatment.

However in a fellow eye affected by lattice degeneration where detachment has already occurred in the first eye, the risk of retinal detachment in the fellow eye is significant and reported to be between 11 and $40 \%{ }^{8.9}$ If horseshoe tears are found in association with lattice degeneration in a fellow eye the risk of progress is greater whether they are symptomatic or asymptomatic and is an indication for preventive treatment. $^{2}$

\section{Traction}

The reason for this increased risk is usually given as traction, but how this operates in either the first or the fellow eye is not at all clear. There is said to be a high incidence of vitreous detachment but this is not always present in either eye, and other vitreous changes are not strikingly different. It is somehow assumed that vitreous detachment increases the traction perhaps by a change in vitreous mobility. This, however, is a considerable assumption.

I have found that tears frequently develop outside areas of obvious lattice degeneration, confirming the observation of others, ${ }^{5,10}$ so that the association of lattice degeneration with so-called tractional tears is not always a direct one but has an important bearing on technique in prophylaxis.

\section{Vitreous detachment}

The role of vitreous detachment in the pathogenesis of retinal detachment remains, for me, a controversial one. It has been stated that vitreous detachment is a major factor in the development of retinal detachment,${ }^{11}$ and undoubtedly some retinal detachments are preceded by an acute and symptomatic vitreous detachment, yet this is not always the case.

Part of the problem relates to what is meant by vitreous detachment. Slit-lamp examination of the vitreous often shows fragmenta- 
tion of the gel with apparent separation from the retina; this is not a vitreous detachment. A true vitreous detachment is a specific pathological entity related more to the retina than to the vitreous within the vitreo-retinal interface.

Figure 1 illustrates a true vitreous detachment, showing a very distinct membrane lining the posterior surface of the gel. This is the posterior hyaloid membrane. It is tough and inelastic and has a crinkled surface; it usually has a hole in the middle of varying size where it has separated from the opticdisc, and it always remains attached to the peripheral retina at about the level of the equator. A true posterior hyaloid membrane should not be confused with the indistinct, surface of fragmented gel.

Studies including those of Okun ${ }^{12}$ have shown that the internal limiting membrane of the retina detaches with the vitreous in a posterior vitreous detachment. This probably matters a great deal for the basal lamina of the retina is membranous and collagenous and gives considerable structural integrity to the retina.

The observation also that the basal lamina is absent over areas of lattice degeneration as well as other predisposing lesions ${ }^{2}$ would suggest that this change in structural integrity of the retina in these and other areas of the peripheral retina might account for some of the discrepancies in the link between traction, vitreous detachment and retinal pathology in the pathogenesis of retinal detachment. I believe that we have not yet begun to address the problems of the pathogenesis of retinal tear formation. The results of animal experi-

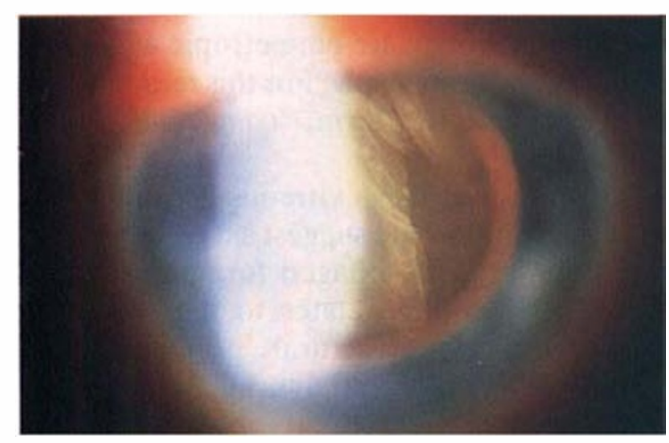

Fig. 1. mentation relating vitreous breakdown and retinal break formation ${ }^{13}$ do not correlate with human clinical experience. There is still much to be learnt about the underlying pathology of retinal detachment especially in the field of structural changes related to what is now called retinal degeneration.

\section{Symptomatic vitreous detachment and risk}

Studies following the course of acute symptomatic vitreous detachment would suggest that after the first few weeks it is unlikely that a retinal tear will develop,,$^{7,5}$ although the risk may continue until all symptoms have disappeared. From this and other studies we can also conclude more importantly that if an asymptomatic vitreous detachment is found in any eye with a flat retina, especially perhaps a fellow eye, then that eye is no longer at risk of developing a retinal detachment.

I have practised this policy in prevention for the last twelve years and have never seen any patient who has been found to have an established asymptomatic and uncomplicated vitreous detachment go on to develop a retinal tear or detachment.

It is mandatory to establish whether or not a true vitreous detachment exists by demonstrating the posterior hyaloid membrane before giving an assessment of zero risk. This is not always an easy matter and may entail very careful study of the vitreous using the slitlamp and 90D indirect lens.

\section{High Risk Cases}

We have considered cases at very low risk of retinal detachment where the need for treatment rarely arises. We must now discuss high risk situations.

One of the most challenging problems in retinal surgery is presented by giant and other complex retinal tears. They may take many different forms and most often cannot be treated by conventional scleral buckling surgery.

\section{Giant retinal tear}

Most complex tears occur spontaneously in eyes with severe abnormalities of the vitreous body and with serious structural defects in the peripheral retina. In the case of a giant tear the anterior flap forms by a separation of the 


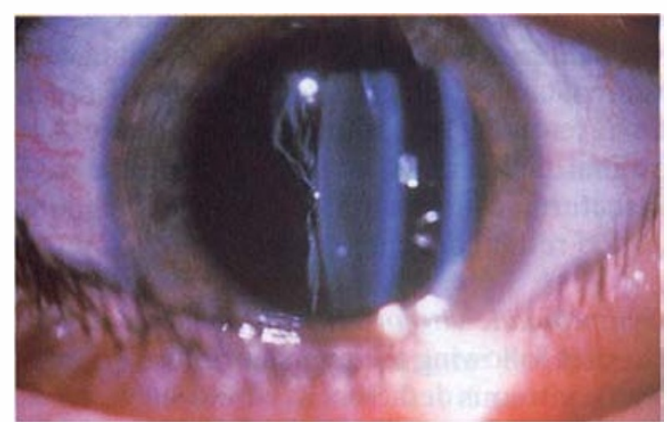

Fig. 2.

pars plana with a splitting of the retina at the ora, so forming the anterior flap; the posterior flap forms secondarily.

Occasionally the split occurs circumferentially behind what ophthalmoscopically appears to be the ora serrata and very rarely in a radial direction suggesting that there is a serious problem with retinal structure. In oral tears posterior extensions commonly develop at the apices of the tear as a result of movement of the posterior flap.

\section{Congenital vitreous anomaly}

There are two main varieties of vitreous anomaly found in affected patients. The first occurs in young and highly myopic patients in whom there is no significant family history. The vitreous cavity contains fibrillar fragments of abnormal gel only, and this anomaly is almost certainly congenital. How this relates to the structural retinal problems leading to a giant tear is not obvious since useful histology has not yet become available.

The risk is very hard to identify in these patients before the first eye detaches, but suspicion should be aroused in a highly myopic child if severe vitreous abnormality is found on slit-lamp examination.

The second variety has a more characteristic vitreous abnormality which allows the risk factors to be more easily identified. Figures 2 and 3 illustrate the changes in which the vitreous is represented by a narrow zone of gel lying behind the lens to which it is attached, and this is separated from an optically empty space by a very well defined membrane which is either attached to the periphery of the lens or merges with basal gel attached to the pars

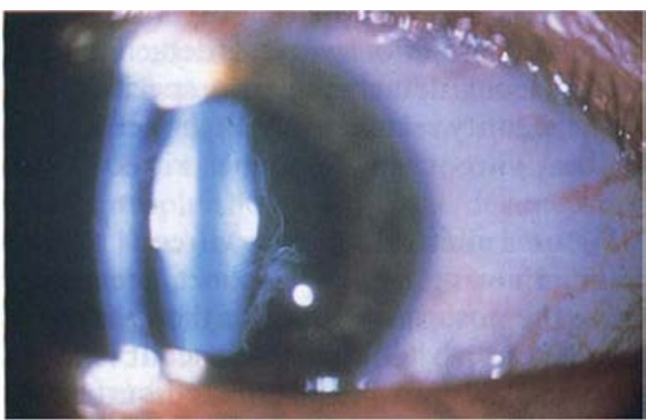

Fig. 3.

plana. The exact nature of the membrane in this anomaly is not entirely clear but there is a striking resemblance to the membrane separating primary and secondary vitreous in an otherwise normal eye. It is likely therefore that the primary vitreous probably develops normally in this anomaly.

The apparently empty space behind the membrane appears to be due to the absence of secondary vitreous. Hyaluronic acid estimations of fluid collected from this space at surgery indicate that it is present, although the concentration is variable. This would suggest an absence of the collagenous component of the secondary gel.

The complete picture in this interesting anomaly is pathognomonic and should not be confused with any other vitreous abnormality.

\section{Congenital megalophthalmos}

A further ocular feature of these patients is that they have very large eyes. Ten years ago I described congenital myopia and complex retinal detachment in children. ${ }^{14}$ Further experience has shown us that not all these patients are myopic; many are emmetropic and a few are even hypermetropic. For this reason I now prefer to use the term, 'congenital megalophthalmos'.

The fact that these vitreous abnormalities are congenital would suggest a developmental defect in Type II collagen formation within the eye. How this relates to the large eye where massive structural problems may develop within and on the surface of the retina is still to be evaluated, but it becomes a little easier to understand when we look at the 
associations of congenital vitreous anomaly with systemic disease.

\section{Systemic associations}

There is a wide spectrum of abnormality associated with congenital vitreous anomaly. Facial, joint and other changes are found, and range from what has become known as Stickler's syndrome to such conditions as spondyloepiphyseal dysplasia; in many of these patients a defect in Type II collagen synthesis is already being identified. ${ }^{15}$

I have had the opportunity to study more than 300 cases of congenital vitreous anomaly associated with various systemic abnormalities over the last 15 years. Not all have giant tears but most have presented with complex retinal detachments, often in childhood, and some have been members of affected families.

There is a very wide variety of systemic abnormality found throughout this group of

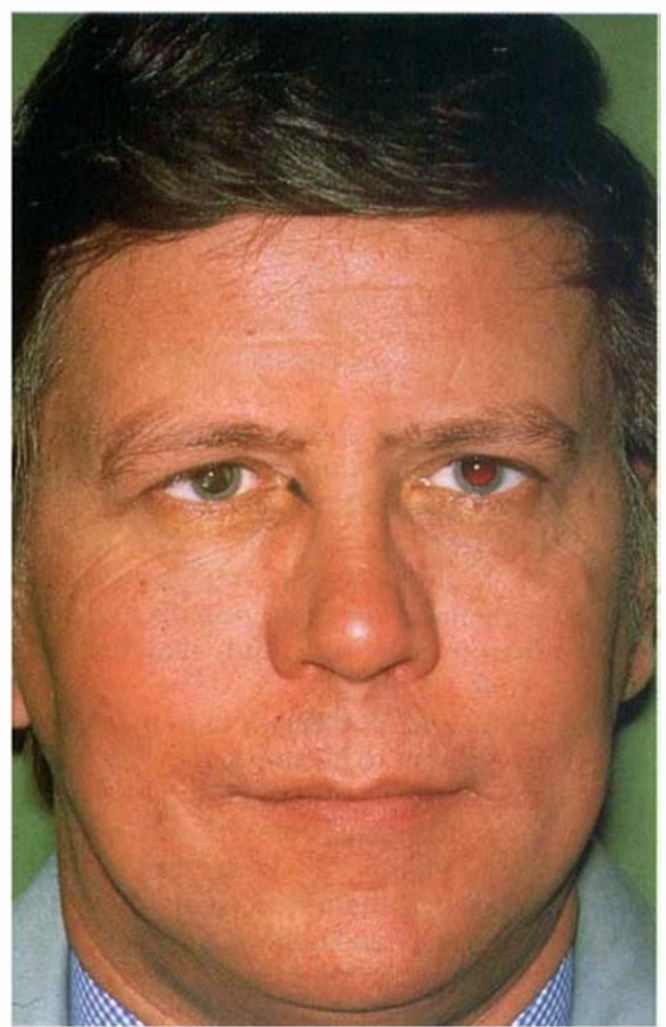

Fig. 4. patients. Most cases do not show any obvious family history although careful questioning will often reveal features which might indicate that a family member had been affected by some manifestation of congenital collagen disease. Where a family history exists it is usually dominant and within affected families there is a great variety of expression of the disease.

Figures 4 and 5 show the face of a man affected by nuclear cataract of very early onset; his son, depicted in Figures 6 and 7, is affected by the Pierre-Robin syndrome and detached the retina of one eye at the age of 9 . At this stage the diagnosis of congenital megalophthalmos was made and a daughter, illustrated in Figures 8 and 9, was identified as having the same problem although her retinas were not obviously abnormal. All these family members had the typical vitreous anomaly and facial changes.

Figures 10 and 11 show another family

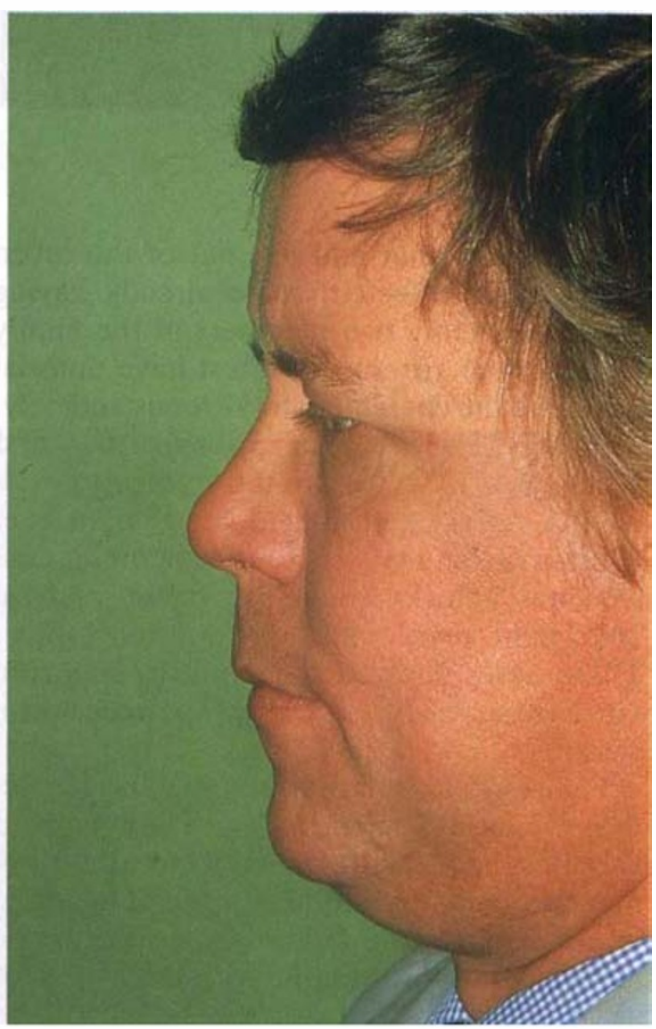

Fig. 5. 


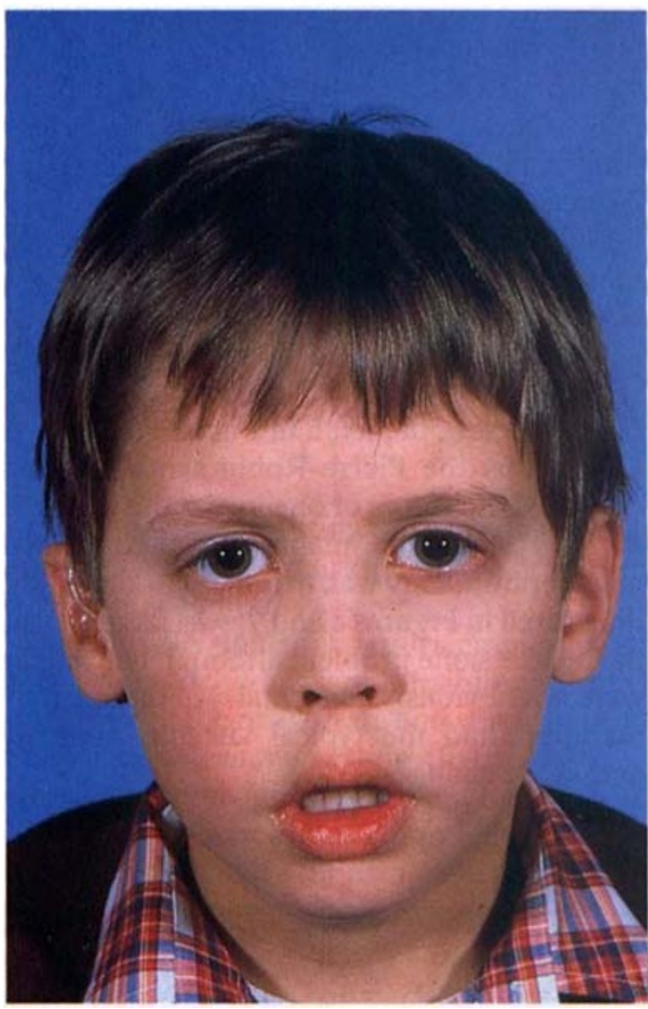

Fig. 6 .

where the mother and five out of the seven children are affected, some already having giant tear. Only two members of the family have normal vitreous, the rest have unusual faces and the characteristic vitreous anomaly.

Figure 12 shows a family which was first reported in $1972^{16}$ before the youngest developed a retinal detachment in his right eye. Figures 13 and 14 shows another sporadic case who was unlucky enough to suffer bilateral $360^{\circ}$ giant tears which proved inoperable. These cases showed the typical congenital vitreous anomaly, and more extreme facial changes.

Figures 15 and 16 show some of the characteristic facial appearances, consisting of variable abnormalities of nasal bone development, ranging from total absence of the nasal bones at birth to a failure of nasal development beyond the infantile with some cases of abnormal broadening of the bridge of the nose.

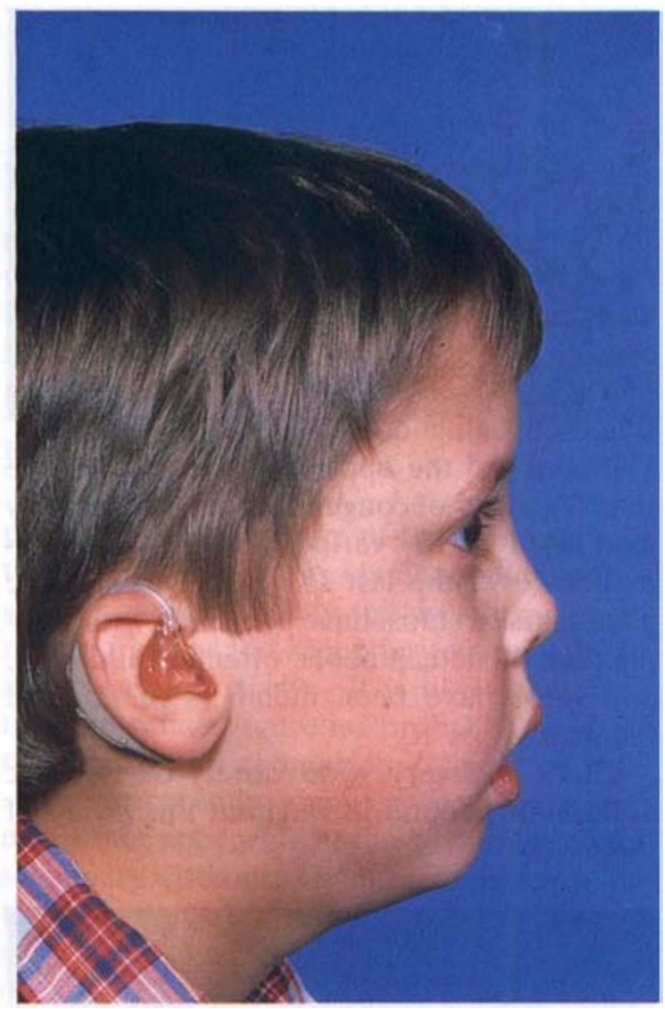

Fig. 7.

Figures 17 and 18 show the more variable changes in maxillary and mandibular bony development. The maxilla was often flattened with long alveolar processes and the mandible underdeveloped.

Figures 19 and 20 show a remarkable variation which exists within one family, where a patient with giant retinal tear and only slight facial changes has a brother who has the Treacher Collins syndrome. Both show typical congenital vitreous anomaly and also a characteristic localised and lamellar lens opacity (Fig 21).

Figures 22 and 23 shows a patient who was originally thought to be affected by Crouzon's syndrome until a severe retinal problem occurred, at this stage the typical congenital vitreous anomaly of congenital megalophthalmos was identified. This diagnostic problem had occurred before in the case of the patient depicted in Figure 13, despite the absence of the characteristic radiological changes of Crouzon's disease. 

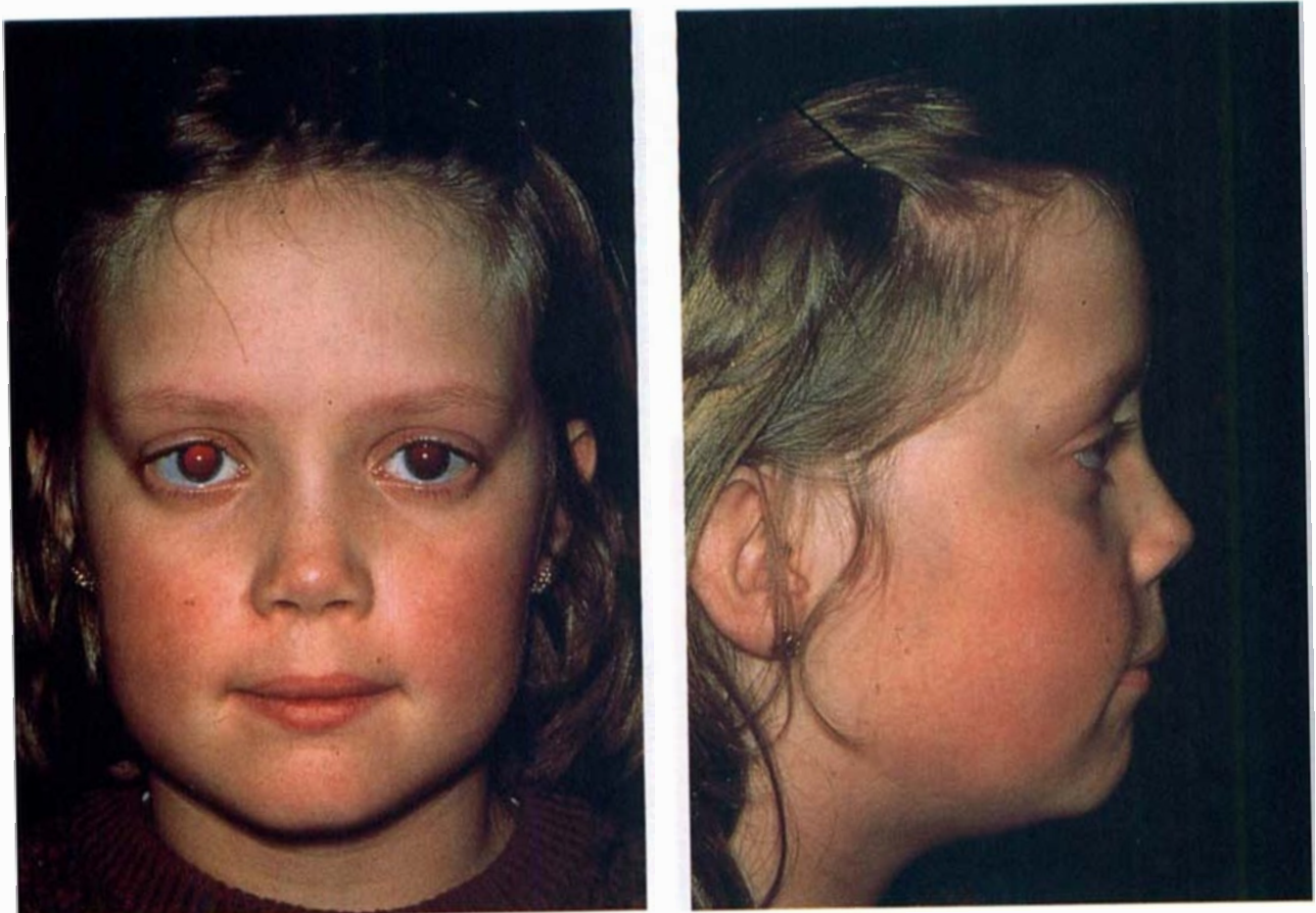

Fig. 8.

Fig. 9.

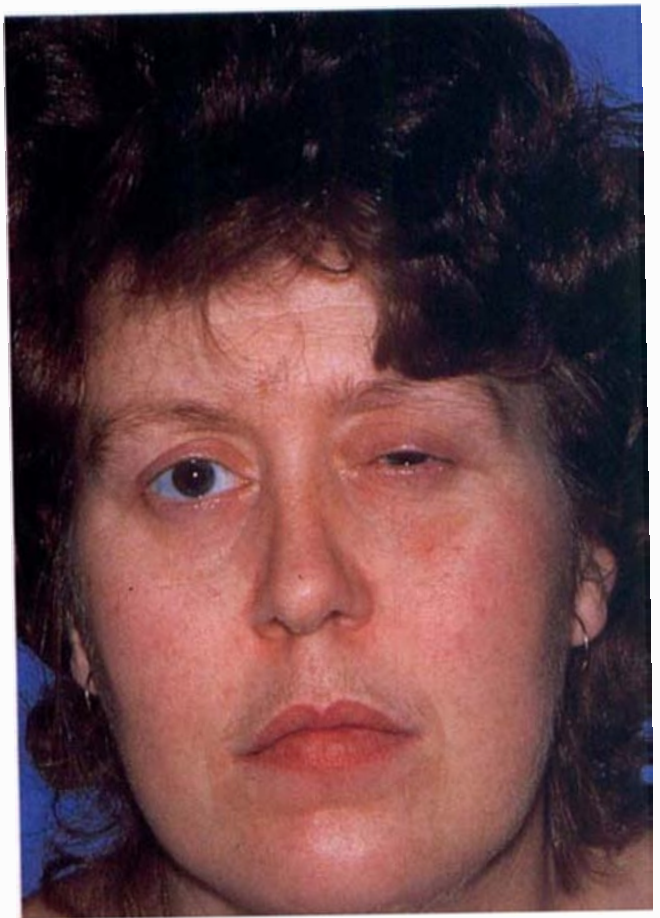

Fig. 10.

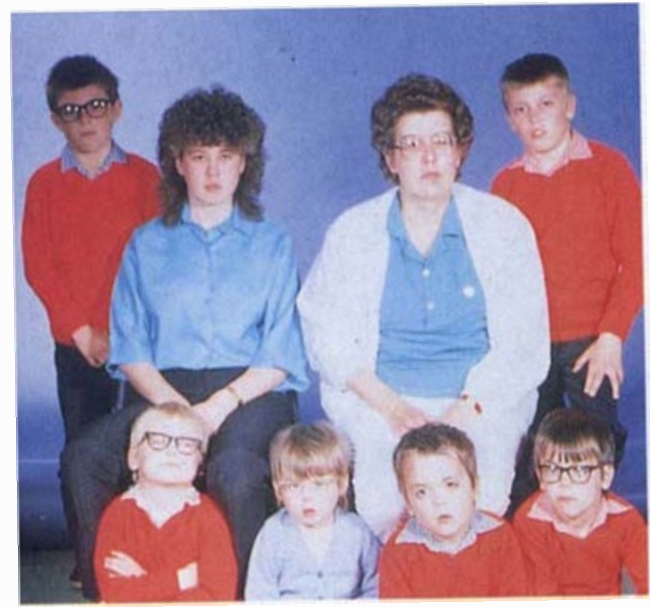

Fig. 11. 


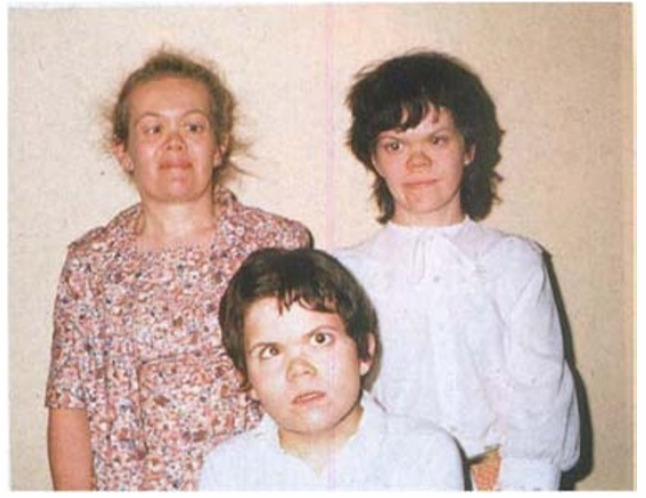

Fig. 12.

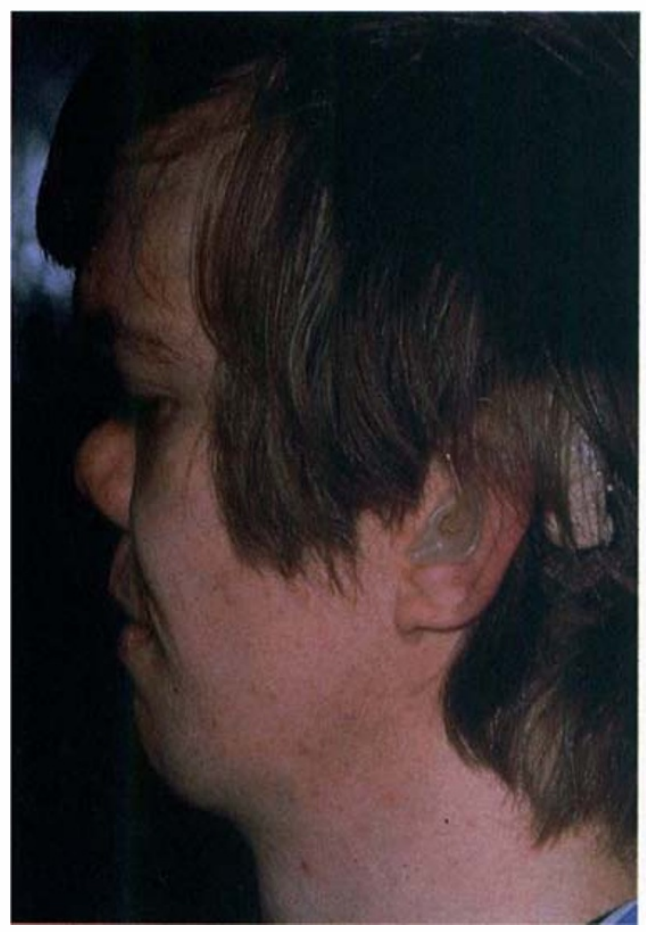

Fig. 14.

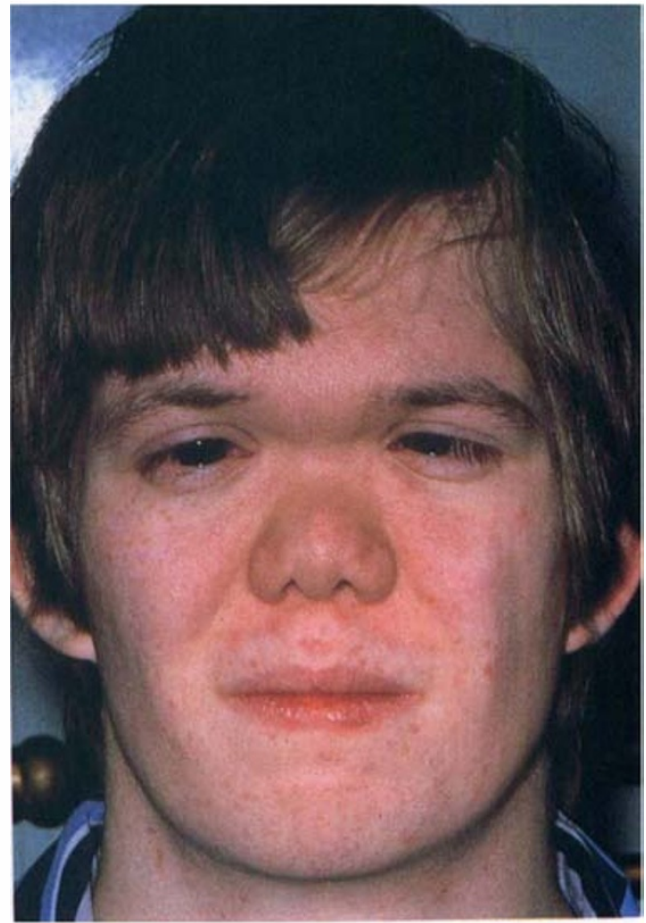

Fig. 13.

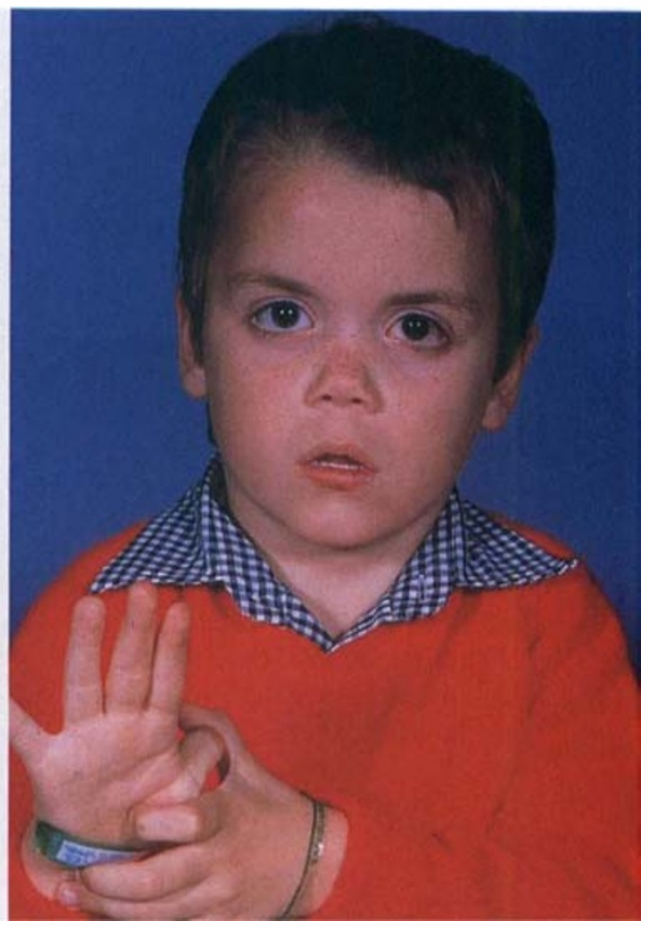

Fig. 15. 

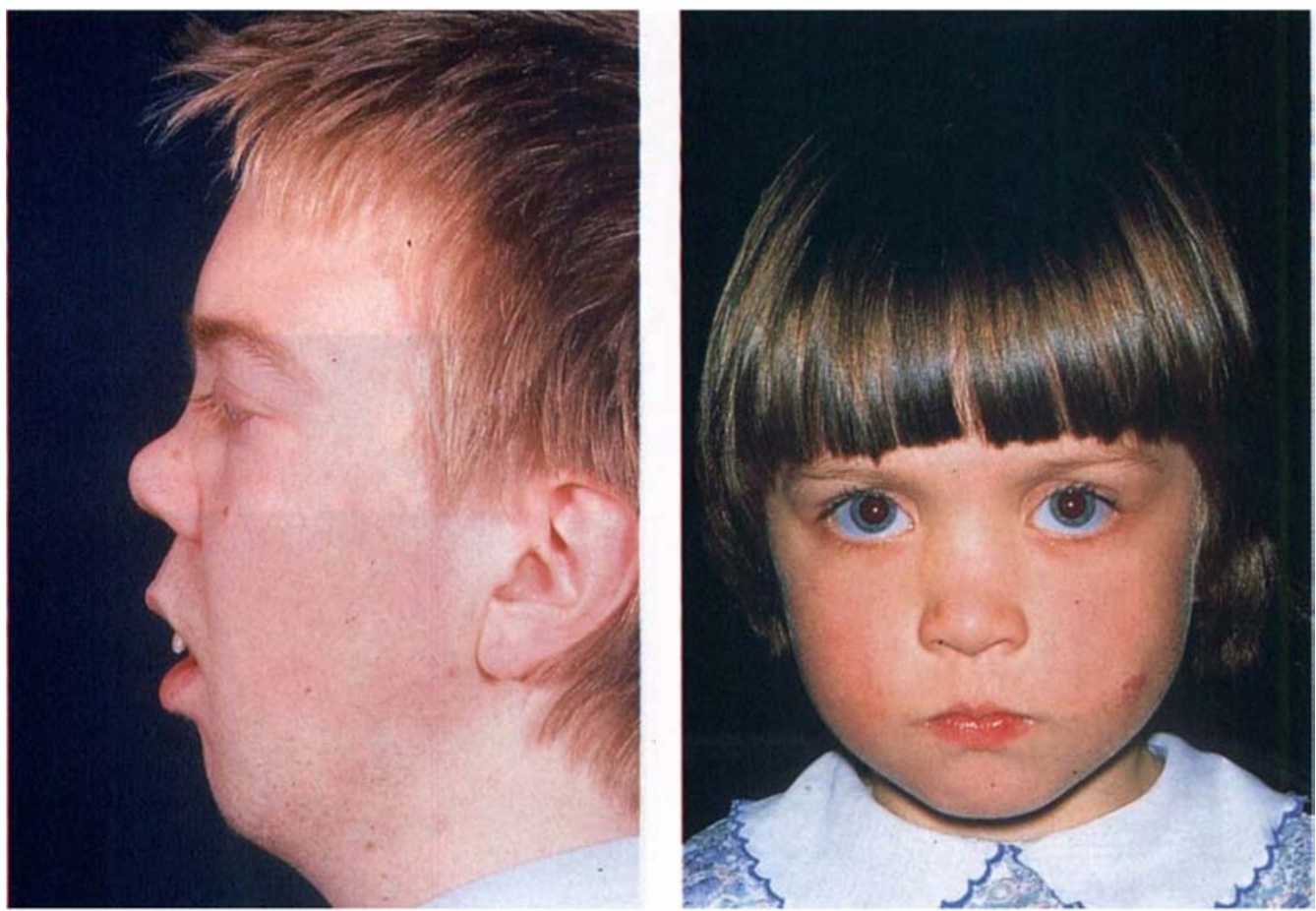

Fig. 16.

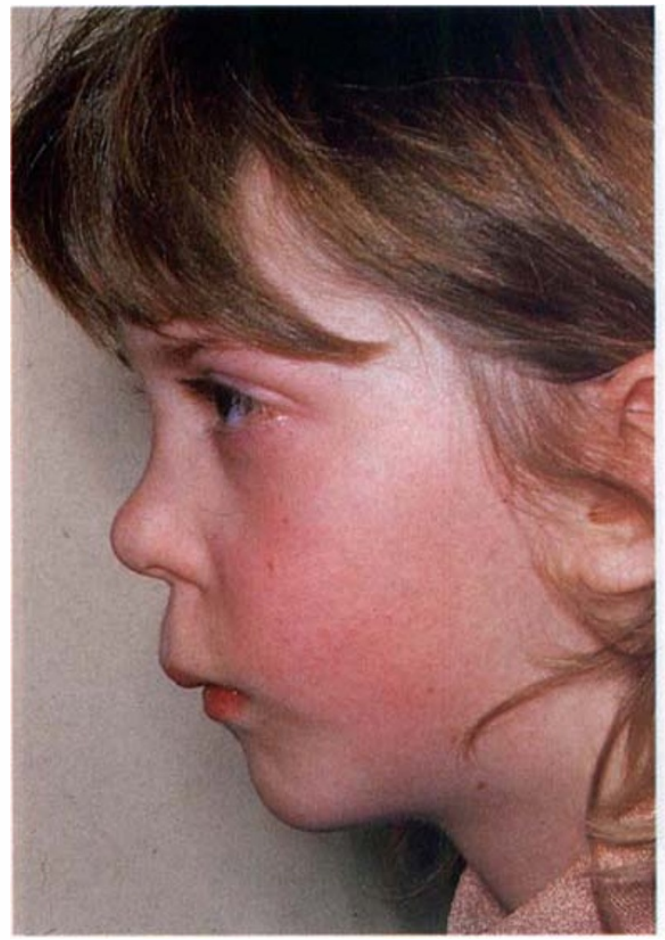

Fig. 17.

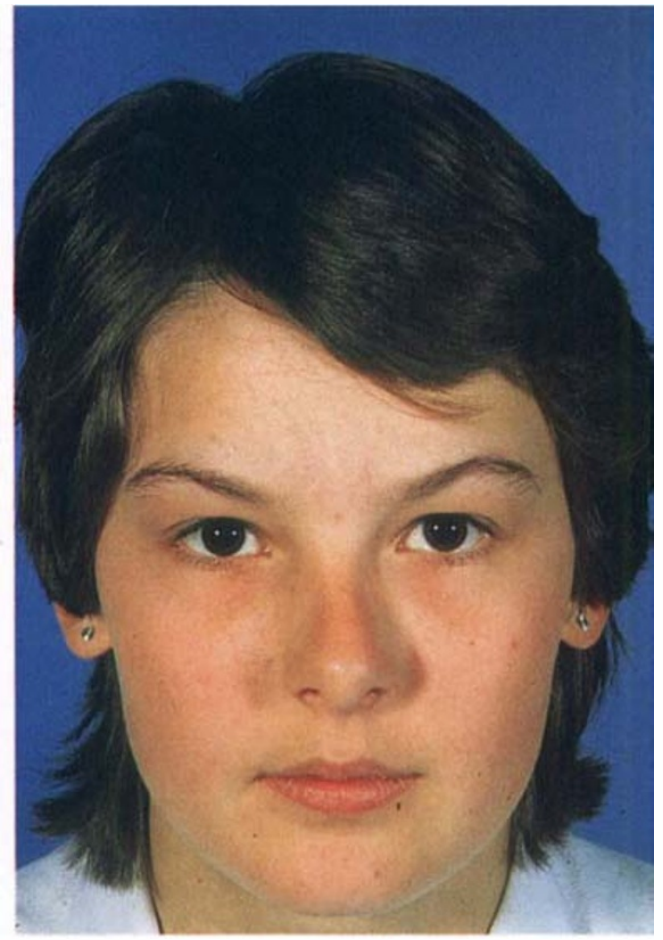

Fig. 18.

Fig. 19. 


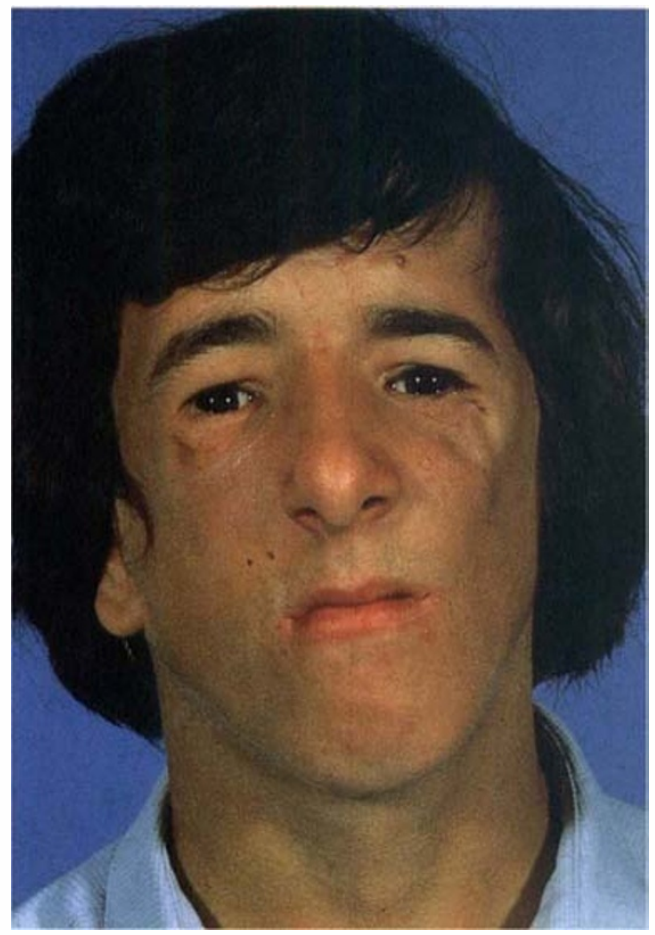

Fig. 20.

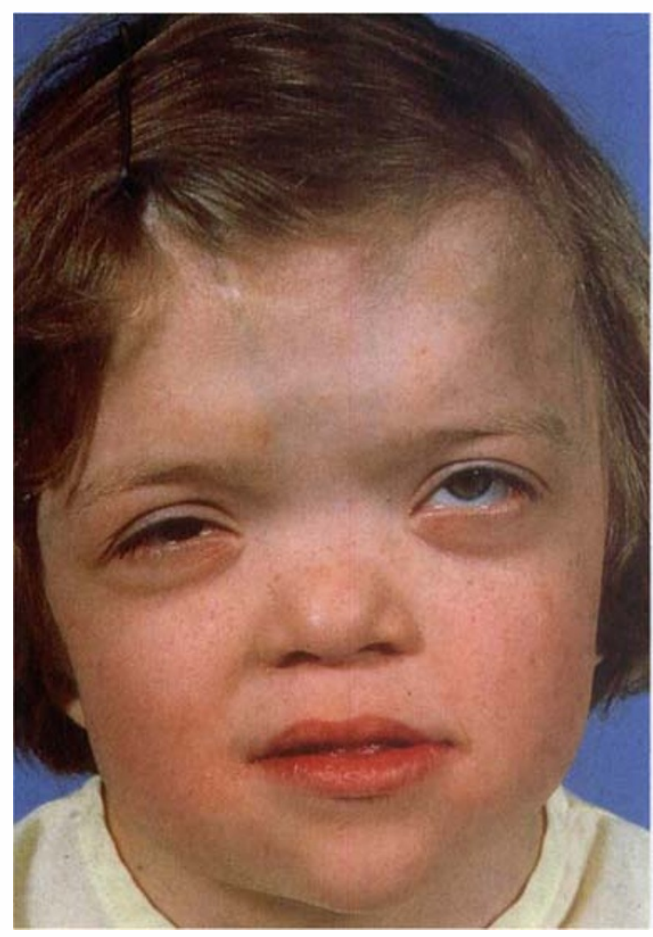

Fig. 21.
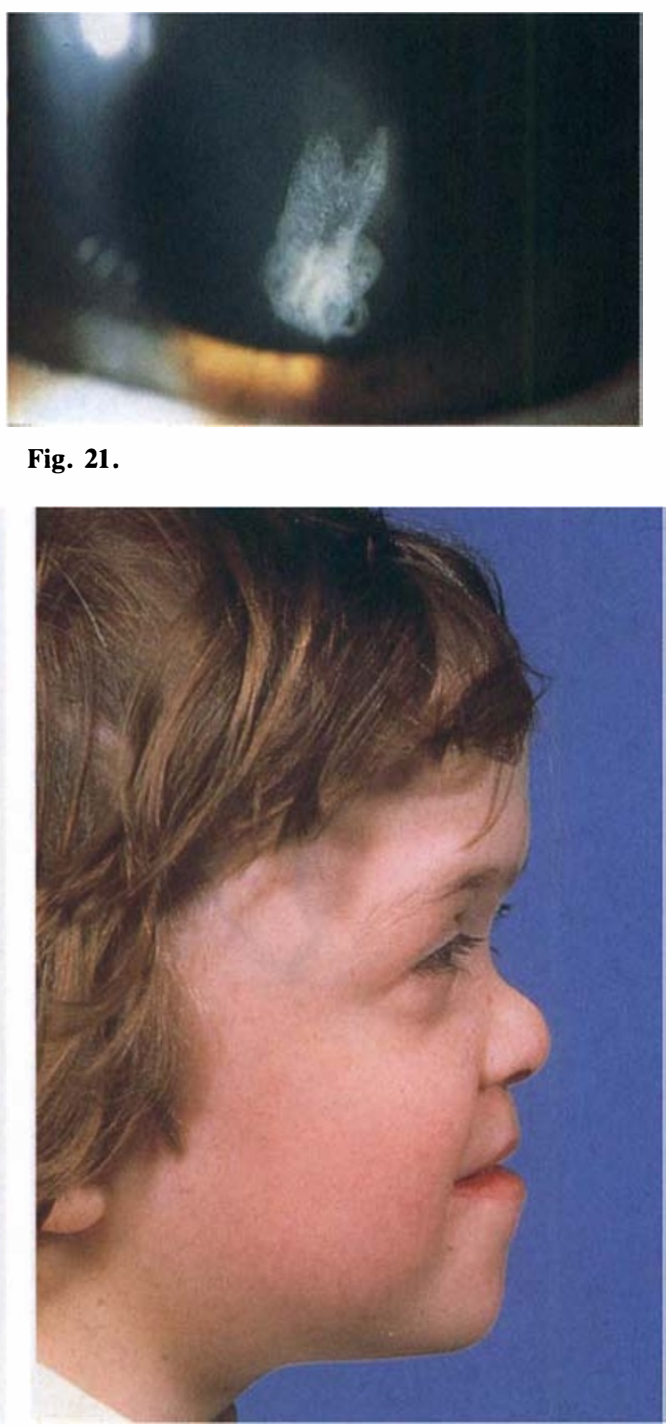

Fig. 22.

Fig. 23. 

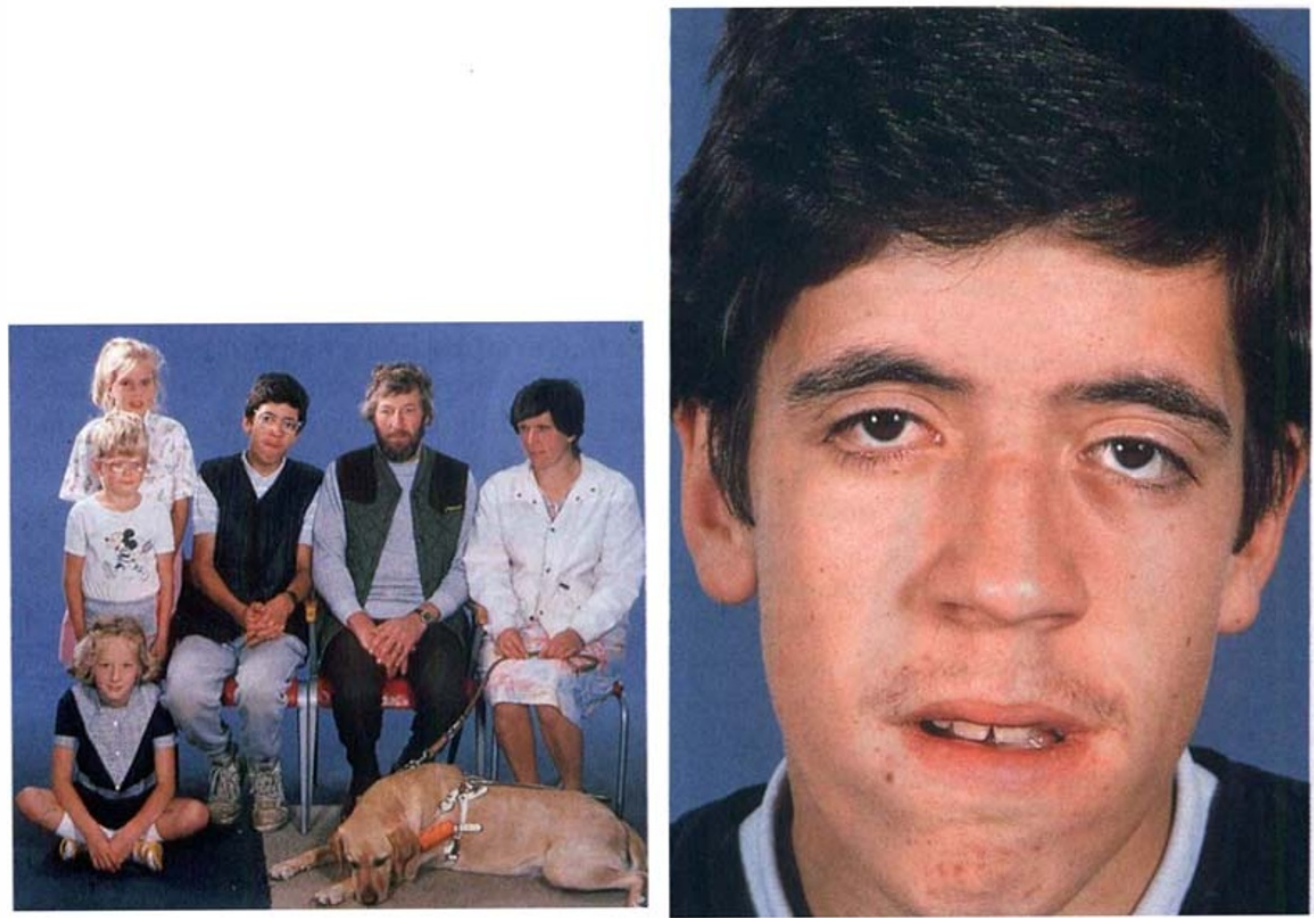

Fig. 24 .

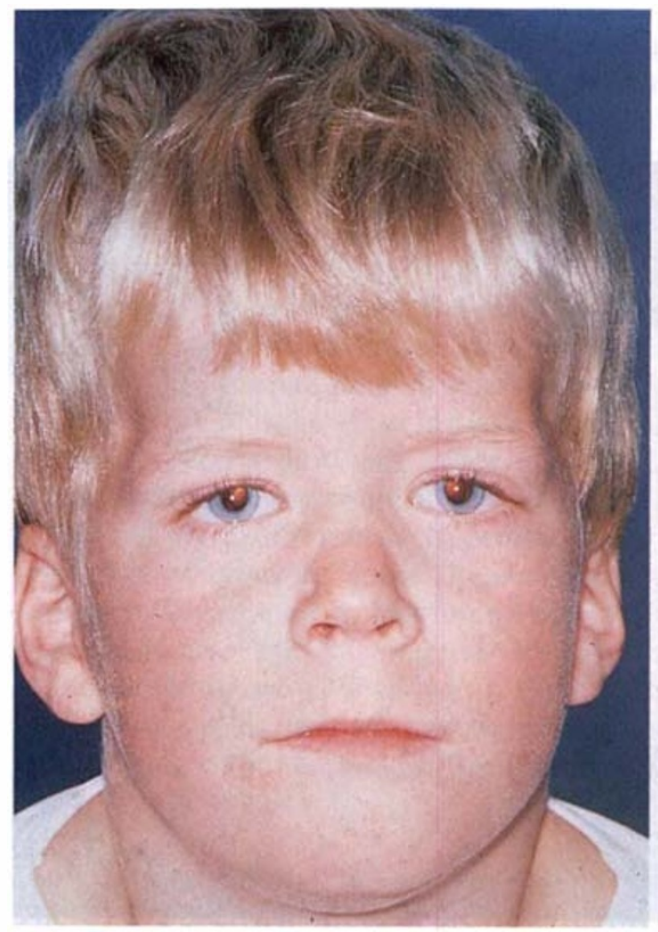

Fig. 25 .

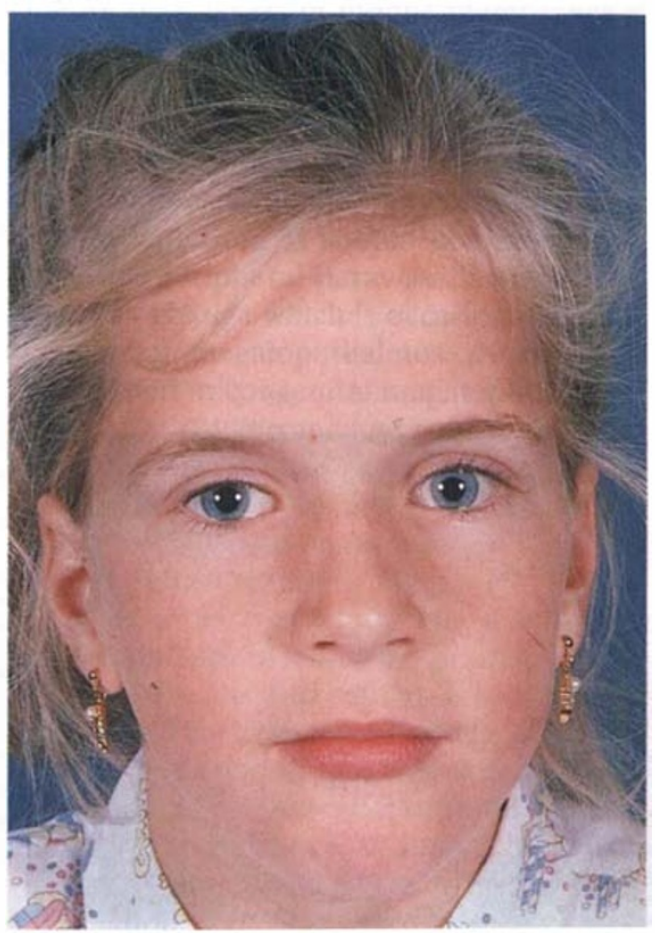

Fig. 26 .

Fig. 27. 


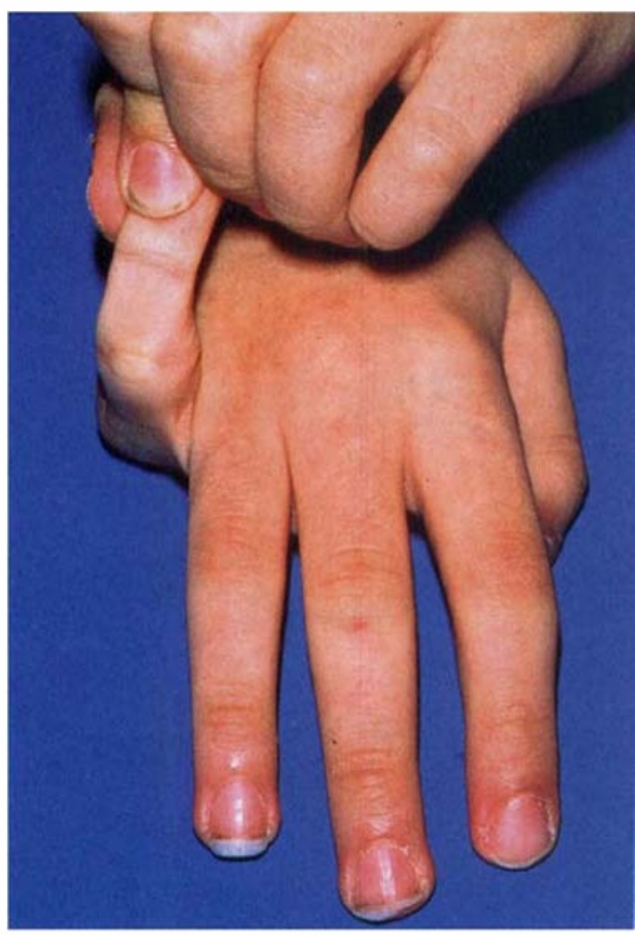

Fig. 28.

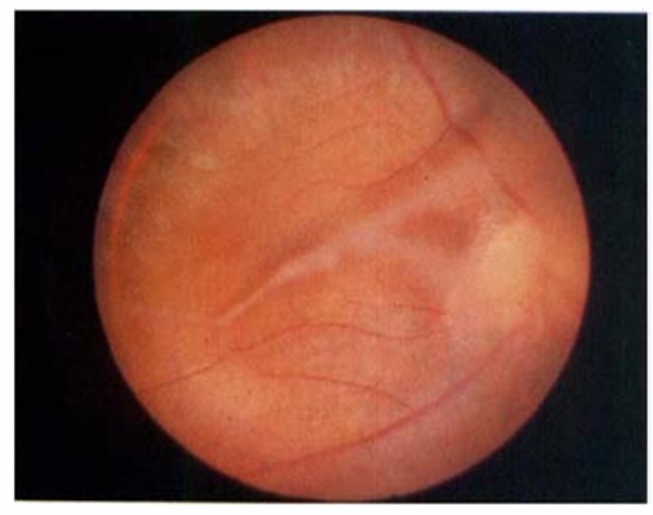

Fig. 30.

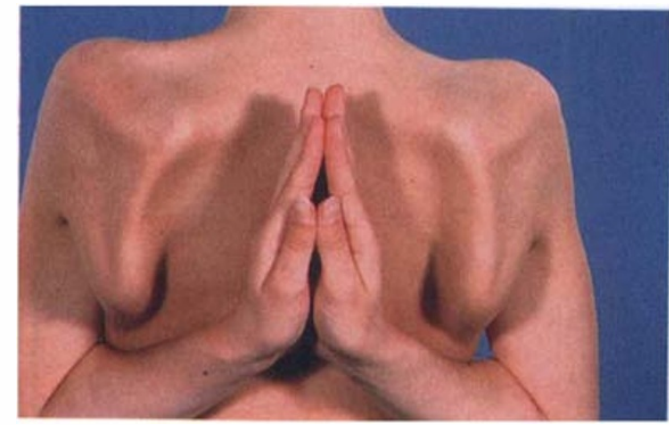

Fig. 29.

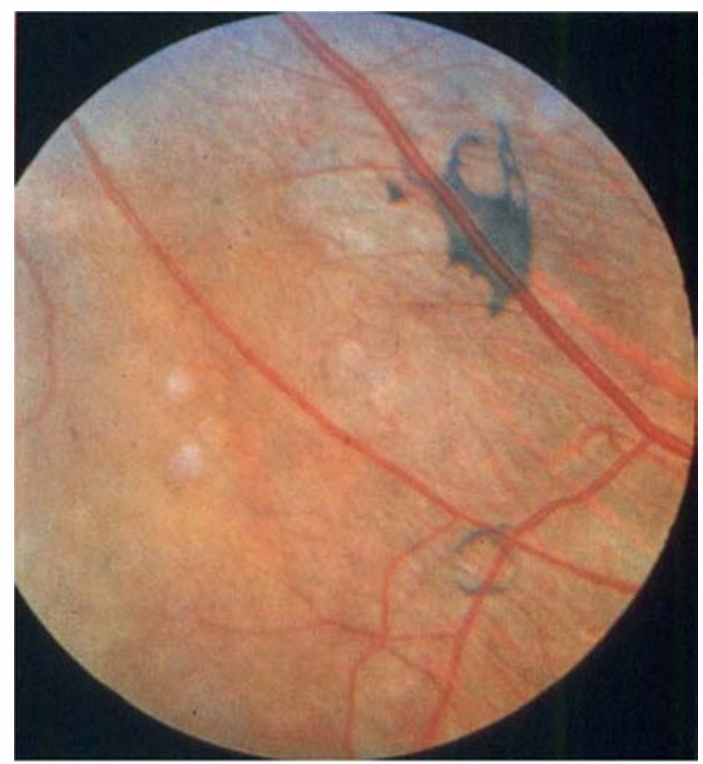

Fig. 31 . 
A high arched palate was usual and many cases had already undergone repair of a cleft palate, however where the Pierre-Robin syndrome had already been identified the ocular problems were not suspected until the retina detached.

\section{Marfan's syndrome}

Patients affected by Marfan's syndrome have serious retinal problems and we have had the chance to study a number of cases. Some are familial and some sporadic, and their retinal problems are similar to patients affected by congenital megalophthalmos.

Giant tears and bilateral retinal detachments are frequently seen but the major difference is that their vitreous is not congenitally abnormal and may only show myopic degeneration at the time the retina detaches.

In the case of a giant tear the anterior flap forms from the pars plana as in other varieties of giant tear, but since this does not occur in affected families before the lens dislocates it can be difficult to identify affected individuals at risk without repeated examinations using the slit-lamp. This problem is compounded by variability in the expression of the disease.

Figure 24 illustrates a family with a strong history of Marfan's syndrome and retinal detachment. The mother had bilateral giant tears 20 years ago and is now blind, her eldest son is shown in Figure 25, he is typically Marfinoid and had dislocated cataracts removed at a very early age.

Figures 26 and 27 show two of the three other children from a second marriage who have since developed lens dislocation, one at the age of two and the other at eleven; neither of these patients show any other manifestation of Marfan's syndrome.

Most of my patients with congenital megalophthalmos showed joint hyperflexibility similar to those seen in Marfan's syndrome; limb joints are usually affected, some to a remarkable degree as is shown in Figures 28 and 29. Joint pathology has developed in some young patients and Perthe's disease is not uncommon.

\section{Reported non-ophthalmic associations}

There have been a number of previous reports describing retinal detachment with giant tear associated with vitreous and systemic changes. Some refer to the original description of the Marfan-like appearance of the Stickler syndrome, ${ }^{17}$ and cleft palate has been described in association with giant tear. ${ }^{18}$ Other reports link the retinal changes of Wagner's syndrome with the systemic features of some cases of what is called Stickler's syndrome. ${ }^{19,20}$

All describe the vitreous changes as degenerative. This seems to have arisen from the idea that what is termed 'optically empty vitreous' is a single entity and the result of degeneration.

\section{Vitreous degeneration and congenital anomaly}

The vitreous anomalies seen in these patients are not degenerative; since they are consistent and found in very young children they are undoubtedly congenital and the result of abnormal vitreous development.

In Wagner's syndrome the anterior vitreous immediately behind the lens may be empty or represented only by fragments of gel. Figure 30 shows posterior vitreous which is grossly malformed; layers of mobile membranes are seen which take the form of fenestrated sheets and these are associated with a characteristic retinal pigment epithelial change (Fig 31).

This may be very marked and some members of affected families may suffer defects of dark adaptation. It should not be confused with the peripheral paravascular retinal pigmentary change which is occasionally seen in congenital megalophthalmos. Nyctalopia is never seen in congenital megalophthalmos.

Wagner's syndrome and congenital megalophthalmos are two separate entities distinguished by distinct, different and congenital vitreous abnormalities. The risk of retinal detachment in Wagner's syndrome appears to be very low but in congenital megalophthalmos it is very high. If one parent has the disease and retinal detachment the chances of an affected offspring developing retinal detachment is $60 \%$ whereas if an affected parent has not suffered a retinal detachment the chance is $40 \% .^{16}$

Stickler described severe joint changes in association with high myopia and retinal detachment, but no facial abnormality. ${ }^{17} \mathrm{His}$ 
ophthalmologist found congenital myopia with no other apparent ocular defect.

Marshall ${ }^{20}$ collected a group of patients with facial changes, cataract, glaucoma and hearing problems, but no retinal detachment. He noted that whilst many of the facial characteristics were similar to those of the anhidrotic type of ectodermal dysplasia there were no skin problems and concluded that this was not the basic problem.

(It is a noteworthy coincidence that Marshall published his observations in the issue of the American Journal of Ophthalmology which honoured Sir Stewart Duke-Elder on the occasion of his sixtieth birthday.)

\section{Stickler and Marshall syndromes}

There has been much discussion in the literature surrounding a possible link between Stickler's and Marshall's syndromes, and there is very little agreement. It may very well be that all are due to variable expression of a single gene mutation, and indeed the two main variaties of congenital vitreous anomaly may represent this variation. The complexities of the problem are immense and can only be solved by careful genetic studies using known genetic markers.

From the ophthalmological point of view the problem is perhaps a little easier to understand. There is a wide variety of joint, facial and skeletal abnormality associated with congenital megalophthalmos and a pathognomonic vitreous anomaly, with features of both Stickler's, Marshall's and other syndromes. For this reason I do not believe that we should be referring to this disorder as Stickler's syndrome.

It would be more appropriate to use the term 'The Congenital Megalophthalmos Syndrome' or 'CMS'.

\section{Prevention in CMS}

The preventive aspects of congenital megalophthalmos lie in the recognition of the typical changes in the vitreous in patients with complex retinal detachment, looking also for evidence of systemic manifestations of a collagen disorder so that the fellow eye may come under suspicion. Family members may be at risk even if they are emmetropic and appear to be normal physically, so that a care- ful examination with the slit-lamp should identify individuals at risk.

Examination of the retina is not particularly helpful. Occasionally paravascular pigmentary changes may be seen and in some children post-oral retinal surface defects may be visible; however the absence of any obvious ophthalmoscopic abnormality does not preclude high risk and indeed in patients at risk of giant tear it is usual to find no peripheral retinal changes at all.

\section{Prevention in Marfan's syndrome}

In the case of Marfan's syndrome the eyes may be affected selectively, so that in family members without any other manifestation of the disease any risk can be identified by looking for early signs of lens dislocation. As in congenital megalophthalmos the retina is unremarkable before it tears so that an examination with the ophthalmoscope gives very little indication of risk.

\section{Prevention in Aphakic Retinal Detachment}

A further interesting aspect of prevention relates to aphakic retinal detachment. Considerable interest was shown in this problem with the advent of extracapsular extraction techniques. Although this method was initially introduced to try to solve the problem of cystoid macular oedema, it was found, as a side-effect, that the incidence of retinal detachment was apparently reduced. ${ }^{21}$ However early hopes that retinal detachment in the aphakic eye might have been eliminated were not fulfilled as increasing numbers began to occur. ${ }^{22}$

The belief that cataract extraction leads to retinal detachment in a significant number of cases has dominated thinking in retinal circles for a very long time. Many reports have described differences between phakic and aphakic retinal detachment and it is widely believed that they are two separate problems. $^{23}$

\section{The paradox}

A number of discrepancies have always troubled me in accepting that a link should exist between retinal detachment and cataract surgery. Most of all the length of time which usually passes between one and the other. If a 
retinal tear occurs at the time of cataract surgery the retina should detach within a few days. Retina surgeons accept that only fresh recently established tears are likely to progress to detachment ${ }^{24.25}$ so that the delay which invariably occurs after extraction and before the retina detaches is very hard to explain. Even in cases where vitreous complications have occurred delays are usual and only a very small number of retinas detach immediately.

The problem of the relationship between cataract and retinal detachment was compounded by a study from St Louis in 1973 where the fellow eye to a detached aphakic eye was followed for up to six years. ${ }^{26}$ Several interesting observations were made. About a quarter of fellow eyes developed a retinal detachment after cataract surgery, and the risk appeared to be halved if the fellow eye was already aphakic.

Of great interest was the group where the fellow eye remained phakic. Seven per cent of these developed retinal detachment before any cataract operation could be carried out.

\section{Case studies}

I thought then that it would be interesting to look at a consecutive series of cases where cataract and retinal detachment occurred in the same patient.

One hundred and five cases were studied prospectively. Of these many cases did follow the usual pattern with retinal detachment occurring after the cataract was removed.

Sixteen had undergone intracapsular extraction, four with known vitreous loss.

Twenty had undergone extracapsular surgery, two of these were found to have vitreous in the anterior chamber despite intact capsules.

Two patients had undergone intracapsular surgery in one eye and extracapsular surgery in the other. In one of these bilateral detachments occurred and in the other it was the eye with the uncomplicated extracapsular operation which went on to detach.

There were many patients who did not follow the usual pattern of detachment following extraction. The variations were many but could be divided into four main categories:

The first was those who had undergone cat- aract surgery in one eye, and later developed a retinal detachment in the phakic fellow eye. There were 12 in this group which can be illustrated by the following case:

A 58-year-old man underwent extracapsular extraction in his right eye in 1987. His retinal detachment occurred in the phakic fellow eye a year later and proved difficult to treat because of dense nuclear cataract. The retina in the aphakic eye has so far remained flat.

There were those who had developed a phakic retinal detachment in the first eye, then underwent cataract surgery in the fellow eye which later detached. There were 16 in this group.

One patient in this group was an Australian professor aged 54 years. He had suffered a retinal detachment in his phakic right eye in 1980; seven years later he underwent extracapsular cataract surgery to the fellow eye. A year after this he had a YAG capsulotomy and 10 days later detached the aphakic eye.

In a similar case, a patient suffered a phakic retinal detachment in 1984 and had the cataract removed two years later; a year after this the fellow eye underwent cataract surgery only to suffer a retinal detachment in that eye six months later.

The next group of patients had a phakic retinal detachment in one eye and then developed a cataract in the fellow eye which was operated without subsequent retinal detachment. There were 10 patients in this group.

An example of this situation occurred in a patient aged 53 years who suffered a phakic retinal detachment in his right eye in 1977. At that time the lens was clear but the fellow eye had a very dense nuclear sclerosis. By 1987 we had plucked up enough courage to carry out an extracapsular extraction which proceeded uneventfully. By 1988 the originally detached eye had developed severe nuclear sclerosis and the lens was removed with good recovery of vision.

A variant of this theme occurred in a 57-year-old physiotherapist; his left retina detached in 1986 when both lenses were clear. He rapidly developed nuclear sclerosis in the fellow eye and the lens was removed in 1988. The lens of the detached eye has remained so far. 
The final category was a group of patients who had a retinal detachment complicated by significant cataract. There were 31 in this group. The cataract was regarded as significant if it had already caused a long-standing visual problem or had been under consideration for cataract extraction before the retina detached. Four of these had actually been admitted for cataract surgery when the retinal detachment was discovered after the patient complained of sudden further loss of vision a short time before admission; in one case it happened the day before.

In the two others the retina detached in the eye awaiting extraction whilst on the waiting list for surgery. This group can be illustrated by the following two patients:

A 48-year-old woman had undergone a successful left extracapsular cataract extraction, she was admitted for the same procedure for the right eye but on admission was found to have a right retinal detachment.

A 59-year-old man had bilateral nuclear and posterior subcapsular cataract. His right retina detached whilst waiting for cataract surgery and was repaired with some difficulty due to problems in visualising the retina.

In summary then, out of 105 consecutive patients combining retinal problems and cataract, 38 cases did not follow the usual pattern of retinal detachment following extraction. Of the rest 36 did follow the rules and 31 had cataract complicating retinal detachment.

Most of the cases in this series were affected by nuclear cataract which was the main indication for cataract extraction; and most had developed significant cataract before the age of 60 years.

\section{Capsulotomy}

The question of the influence of YAG capsulotomy on the risk of detachment frequently arises. In the days of intracapsular extraction emphasis was laid on the need to maintain the integrity of the vitreous face at the time of surgery, despite the very high incidence of late rupture of the anterior face without apparent harm to the retina. Nowadays with extracapsular surgery similar thoughts are turning towards the possible complications of capsulotomy.

Several studies have described the occur- rence of retinal detachment some time after laser capsulotomy, ${ }^{27.28 .29}$ however thousands of laser capsulotomies have been performed with very few recorded post-treatment detachments. ${ }^{30}$ The estimated risk is less than $1 \%$ and in most cases there is a high risk situation such as retinal detachment in the fellow eye.

In this study four out of 20 detachments occurring after extracapsular extraction had undergone capsulotomy, one by surgery and three by laser; two of these had already suffered a phakic detachment in the fellow eye, and the other two were highly myopic.

It will be interesting to look prospectively at high risk cases where laser capsulotomy may be required to see whether there is indeed an increased risk of the retina detaching soon afterwards or whether the few cases seen so far are the result of coincidence.

\section{Conclusions}

I had started this investigation in the belief that the reason why the apparent differences in the incidence of retinal detachment after intracapsular compared with extracapsular extraction was one of time. It was possible that patients undergoing extracapsular surgery were being operated at a much earlier stage in the evolution of their cataract than before, and that, in time, the incidence would be the same. I had not expected that so many cases would be found to have broken the rules.

As a result, I have had to change my ideas regarding the relationship between cataract and retinal detachment. There does appear to be an association between the two, but the apparently random order in which cataract, detachment and extraction may occur in certain groups of patients would lead to the conclusion that it is not the operation to remove the cataract which is significant.

In some patients it may only be coincidence that a detachment occurs some years after an operation to remove a cataract; and this may be the case in an elderly patient where the chance of undergoing cataract extraction is significant.

The present study shows that there is a group of young patients at particular risk of both cataract and retinal detachment, and 
these are typified by the patient who develops rapidly progressive bilateral nuclear cataract before the age of 60 years. Either the detachment or the cataract may present first, and the finding that several patients developed their detachment shortly before the cataract was due to be removed was interesting, had their cataracts been removed by chance a few weeks before they would undoubtedly have been labelled aphakic retinal detachment.

We can only speculate about the link which appears to exist between these two conditions; it is possible that myopia may play a part, perhaps associated with specific pathological changes which may lead to a high risk of both problems developing in the same eye. The embryological relationship which exists between retina and lens continues into adult life where proliferative changes in retinal pigment epithelium are associated with lens epithelial proliferation leading to acute cataract following proliferative vitreo-retinopathy. ${ }^{31}$ Non-proliferative structural and degenerative changes may have a similar relationship where the likelihood of cataract and retinal detachment occurring in either eye in the same individual may be high.

From these findings I have to conclude that there is little evidence that extracapsular cataract surgery has any protective effect on the risk of detachment. There is therefore little point in delaying cataract surgery in a patient who has already suffered retinal detachment after extraction in the first eye, the detachment could easily develop before the operation and consideration should be given to preventive treatment as the first priority.

\section{Prophylactic Treatment}

Having identified a significant risk of retinal detachment it is necessary to consider the possibility for prophylactic treatment. This creates fresh problems; Volume 10 of the System of Ophthalmology summarises the situation perfectly, and I quote: 'The prophylactic treatment of retinal detachments is a somewhat controversial issue' ${ }^{32}$

The reference is, of course, to the use of diathermy and xenon photocoagulation in preventive treatment, but the controversy continues with other methods and it has been hard for us to shake off the fear that any attempt to prevent a problem may not only create its own complication but actually exacerbate the risk of provoking the very condition we are trying to prevent.

There have been a number of reports describing complications following cryotherapy. Some combine prophylactic cryotherapy and treatment of retinal detachment and describe results and complications together without distinction, relating complications to the use of cryotherapy. ${ }^{33}$ Others include photocoagulation and report problems related to both modalities together. ${ }^{34}$

There are two main concerns regarding cryotherapy, first, that it might cause macular complications as were reported after the use of xenon photocoagulation, and secondly that it might cause a predisposing lesion to lead to retinal detachment.

One study described one case of macular pucker after cryotherapy treatment of retinal breaks in over 120 patients. ${ }^{35}$ Another reported six patients where cryotherapy was used to treat the fellow eye of an aphakic detachment. Treatment was very heavy although monitored and retinal detachment occurred in two patients. ${ }^{36}$ This problem was attributed to proliferative vitreo-retinopathy induced by the cryotherapy.

An animal study then followed ${ }^{36}$ which showed that very heavy treatment in a monkey eye could apparently stimulate cellular pre-retinal membrane formation but it was noted that this level of treatment was in excess of that generally used in the clinical situation.

\section{Case study}

I have had the opportunity to review more than 250 patients whom I have treated with cryotherapy with a follow-up of from one to 15 years. In all cases $360^{\circ}$ treatment was given in one session under general anaesthesia, the freezing reaction was continually monitored and allowed to penetrate to the surface of the retina, and great care was taken to avoid refreezing areas of retina already treated at that session.

Treatment was given for a variety of reasons. Some had one or more horseshoe tears or a giant tear in a fellow eye. Some had a family history of congenital megalophthalmos or Marfan's syndrome. The rest were either 
first eyes of patients with high myopia and attached vitreous about to undergo cataract extraction or were fellow eyes to aphakic retinal detachments.

The object of the study was not particularly to show whether or not cryotherapy was or was not effective in any group of patients, but to look at the failures especially to see whether it might be the method of the technique which was at fault; and also to look for any significant complication which might incriminate cryotherapy as a cause.

Eight patients went on to develop retinal detachment between one and 6 years after treatment. In all these examination of the treated retina at the time the retina detached indicated that the treatment had been incomplete and inaccurate.

The most recent case occurred within the last three months. One of a large family with dominant congenital megalophthalmos developed a giant tear in one eye almost exactly a year after $360^{\circ}$ cryotherapy treatment. On examination at the time of surgery it was clear that the treatment was not continuous and had been placed too far posteriorly allowing the anterior edge of a posterior flap to develop. This is illustrated in Figure 29. Movement of this edge had finally allowed the flap to break through the cryotherapy reaction and progress to a retinal detachment.

This, together with three other cases of giant tear, two of whom went on to detach by the same mechanism, has led to the conclusion that it is probably not possible to prevent the formation of the anterior flap in the pars plana in a giant tear. However, it is possible to prevent the development of the posterior flap by more appropriate treatment. The cryotherapy lesions must be placed very close to the ora so that if an anterior flap forms in the pars plana the ora remains securely in place.

Four other detachments occurred in aphakic fellow eyes. These had received equatorial treatment either to areas of white-withpressure or to known predisposing lesions such as lattice degeneration. The retinal detachments occurred as a result of tears forming anterior to a line of incomplete treatment allowing fluid to leak through gaps between the cryotherapy lesions to cause extensive retinal detachment.

In four further cases a symptomatic retinal break developed posterior to the line of treatment as a result of vitreous detachment but did not progress to a retinal detachment; these were treated with laser without further complication.

\section{Complications}

In no case did a tear develop immediately related to a cryotherapy lesion, and none of the treated cases developed any form of macular pucker.

\section{Vitreous detachment as a risk factor}

In considering risk factors related to prophylaxis in high risk cases a careful evaluation of the vitreous is as important as in the low risk group. As well as congenital abnormalities it is necessary to look for true vitreous detachment. In the cataract-related group if the cataract has or has not been removed from the fellow eye treatment must be considered if the vitreous remains attached. If an asymptomatic vitreous detachment with a true posteriory hyaloid membrane can be demonstrated then that eye can be considered to be free of the risk of retinal detachment.

\section{Cryotherapy technique}

The technique for administering prophylactic treatment is important. The problem is in deciding exactly where to place the cryotherapy.

From the St Louis aphakic eye study it would appear useless to treat visible pathology alone ${ }^{26}$ so that only $360^{\circ}$ treatment is likely to be effective. Since breaks may develop in areas of retina not obviously affected by degeneration even if visible pathology is found there is a problem in deciding how extensive the $360^{\circ}$ treatment should be. It is probably sufficient to make the most posterior limit of treatment the posterior edge of observed pathology; if no pathology is found in the fellow eye the treatment should be applied to the observed posterior edge of the vitreous base.

I believe that there is no difference in principle between cases associated with and without cataract. For example in the fellow eye to 
a detachment related to lattice degeneration $360^{\circ}$ treatment should also be given in the knowledge that it cannot be accurately predicted where a break may develop, except that it is likely to lie between the posterior edge of the vitreous base and the ora.

As with all forms of cryotherapy meticulous technique is essential. If inadequate or inaccurate treatment is given the risk persists and this applies especially where focal treatment only is given to obvious pathology.

\section{Prophylaxis in congenital cataract}

One special problem that is worth considering in relation to technique concerns patients who have suffered congenital cataract. We know that they are at high risk of retinal detachment yet we have very few cases upon which to base a firm philosophy of prevention. Most of these are well remembered for their complexity and most had undergone repeated needling surgery for their cataract.

Modern methods have improved the visualisation of the retina after congenital cataract surgery but whether there will be a reduction in the risk of retinal detachment is doubtful. For the same reason as in adult cataract and retinal detachment the delay between the presentation of detachment and lens surgery suggests a problem related to disease rather than operative method or technique.

Whether or not modern surgery is preventive is one consideration but we are still left with a few patients who are affected by or have undergone surgery for congenital cataract and who must be at risk. Prophylactic treatment should be considered in these cases and cryotherapy is the most appropriate modality.

\section{Monitoring of treatment}

Visualisation of the peripheral retina is just not possible in some of these eyes so that if cryotherapy was to be considered it would have to be given without ophthalmoscopic monitoring.

I raise this problem because it illustrates a dilemma which at times occurs in connection with preventive cryotherapy. Should treatment ever be administered without visualisation? I believe that the answer to this is emphatically no. At best such treatment will be effective by luck alone and cannot be justified.

Patients with obscured pupils must be followed very carefully on a symptomatic basis and pupil clearance only carried out as part of any reparative operation if symptoms and ultrasonic investigation indicate that the retina is beginning to detach.

Even in a fellow eye where retinal detachment has already occurred in the first eye it cannot be justified to perform major surgery in the interests of prevention.

The lesson to be learned from these cases is that cryotherapy has to be very carefully applied, in the full knowledge of exactly what it is that we are trying to prevent. To achieve this it is necessary to apply $360^{\circ}$ treatment in a continuous line without gaps; the position of the treatment has to be carefully considered and related to the nature of the potential pathology which is to be prevented.

\section{Rationale of treatment}

The rationale of prophylactic cryotherapy should have as its prime objective the prevention of the formation of retinal breaks. The treatment of established breaks should prevent progress to retinal detachment but at this stage the potential for complication of the break itself is already present.

\section{Prevention in Proliferative Vitreo- Retinopathy}

The next problem which I should like to consider is in the prevention of the most serious complication of established retinal detachment, and this is proliferative vitreoretinopathy.

Proliferative vitreo-retinopathy is widely regarded as an inevitable complication in about $10 \%$ of patients operated upon for retinal detachment. Some attempts have been made to identify causative factors and various aspects of surgical technique have at various times been incriminated.

The concept of inevitability has been further reinforced by an attempt to classify PVR in terms of the maturity and extent of the proliferating membrane. ${ }^{37}$ The classification considers traction alone and is used widely to compare various methods of surgical treat- 
ment; it does not include any factors related to retinal breaks.

About three years ago I reviewed more than 300 cases referred for treatment of recurrent retinal detachment due to PVR and which I had treated using liquid silicone. It was found that about $99 \%$ had persistent open retinal breaks which appeared to be contributing significantly to the current problem.

\section{Case study}

I thought that it would be interesting to investigate the reasons why the breaks remained open in these cases. A study was therefore started late in 1987 looking at patients who had been referred between January 1986 and March 1989.

At the outset it seemed that there were several principle reasons why surgery for primary retinal detachment failed and finally led to PVR. In each case an attempt was made at the time of vitrectomy surgery to analyse the reason for failure of primary surgery and this was then allocated to a category which was stored in a database.

In a few cases neither the referring surgeon nor I could find a causative tear and this was recorded as 'no tear found'.

Where a complication of drainage had occurred, either in the form of a peroperative vitreous haemorrhage at the primary operation or the observation of vitreous and retinal incarceration at the time of vitrectomy it was labelled 'complication of drainage'.

In many cases a plomb had been placed inaccurately to treat a known tear. Some were radial and some circumferential, some plombs had failed due to sutures cutting out or to early infection; and these were all allocated to the 'known tear, inadequate plomb' category.

In some cases there had been unexpected complication, and most of these cases had developed PVR despite accurate scleral buckling so that the causative tear had been pulled away from the buckle.

The largest group consisted of eyes where an encircling element had been placed inappropriately. These included cases where a band had been used in an attempt to close a known retinal break and had failed to do so, or where a band had been placed in a peculiar position for some other reason. In some cases the band had been pulled up very tightly or not at all, and in others the band had been used in a speculative manner to treat a detachment where a break could not be found.

A final group was labelled 'missed tear untreated'. These were cases where the referring surgeon had not found the causative tear or had treated another tear and missed another which went on to cause recurrence.

In all 225 consecutive cases of recurrent retinal detachment complicated by PVR were reviewed. There was no significant difference in distribution between retrospective and prospective cases in any category.

The findings were as follows:

No tear found

10 cases

Complication of drainage

14 cases

Unexpected complication

34 cases

Missing tear untreated

Inadequate plomb

Inappropriate band

64 cases

74 cases

140 cases

Thus in 225 cases there were 336 reasons why the primary surgery failed and only 44 of these appeared unpreventable. Clearly some cases had more than one reason for failure.

In the 'Missed tear' group 12 patients had undergone a speculative encircling procedure. Seven cases had missed tears as well as an inadequate plomb for another tear. Eighteen had a missed tear as well as both an inadequate plomb and inappropriate band for known tears; in most of these cases the band had not been used primarily for tear closure but there had been a serious problem with its placement. The rest had a missed tear problem and complications of drainage or an unexpected complication such as late vitreous haemorrhage.

\section{Missed retinal tears}

One of the difficult questions is whether these missed tears were ever new tears which had appeared after primary surgery. In most cases the pattern of presentation of the recurrence strongly suggests that this was not the case and the discovered tear had been present at the time of the primary operation. Genuine cases of new tears do undoubtedly occur but can only be accepted if an operated case remains stable for some time and is followed by a later recurrence with a new pattern of presentation. 
Why retinal tears are missed in this way is difficult to determine; when asked, it appeared that very few patients had been examined pre-operatively with the scleral depressor. Many patients do not permit adequate preoperative indentation even before the first operation, so that a careful examination under anaesthesia using scleral indentation, before beginning the repair of the detachment is a fundamental step in the prevention of primary failure. The fact that nearly all missed tears were peripheral to the equator and required scleral depression under anaesthesia for visualisation suggests that this method of examination was not widely used in failed cases.

The present study suggested that many cases were treated in the belief that the pathology which was buckled was the primary tear despite the fact that very often the position of the treated lesion did not correspond with the area which might be predicted from the distribution of the sub-retinal fluid.

\section{No visible retinal tear}

There were 10 cases where I could not convince myself that I could see the causative tear. Some of these cases were aphakic and the periphery was obscured by capsular proliferation, and in others it was not possible to be absolutely sure that a retinal break was present despite a careful search before and during surgery. It is imperative in all retinal surgery to be absolutely sure that all retinal tears which are labelled as such are genuine breaks in the retina, it is all too easy to deceive oneself and create an imaginary break in a difficult case.

\section{Complications of drainage}

In the group where complications of drainage were the principle cause of failure the problem was usually due to retinal incarceration at the site of an anterior drainage. Retinal breaks may become distorted by proliferation resulting from such accidents and subsequent neovascularisation may lead to late haemorrhage.

It has been suggested that drainage might be an important factor in the causation of PVR and a recommendation made that drainage should be avoided wherever possible.
There was no evidence from this study that uncomplicated drainage contributed anything at all to the risk of recurrence and in all cases the complication could have been avoided by better technique. There is a far greater likelihood for PVR to result from a failed primary procedure due to a failure to drain where it is necessary, for example in a detachment already affected by early proliferation.

\section{Inadequate plomb}

In the inadequate plomb group the principle difficulty appeared to be in relating the size and orientation of the plomb to the tear or tears. The commonest problem was with the localisation of a circumferential plomb which was often placed too far back and in many cases the cryotherapy lesions had not been accurately applied in relation to the tear or buckle.

There are many varied ideas as to what is required of a scleral buckle, ranging from the huge radial plomb to close a small horseshoe tear to what is called a broad gentle buckle. This reflects the lack of an agreed concept regarding the rationale for scleral buckling.

The broad gentle buckle sounds very good for the eye and is usually created by adding to an encircling band a piece of silicone rubber tyre. Having seen many primary operations fail because of the use of this technique, I do not believe that it is effective as a scleral buckle and never ever use it in primary surgery.

The silicone tyre was designed many years ago as part of an intrascleral method which was combined with extensive diathermy, and this has been abandoned by most modern retina surgeons. As an explant the tyre produces an inadequate scleral buckle, and is a very poor substitute for silicone sponge properly sutured into position and accurately localised over the retinal tear. This is especially so in those many cases where distortion of the tear by early membrane formation requires a deep indentation to ensure complete closure.

\section{Inappropriate encirclement}

The inappropriate band group was the largest one responsible for failure of primary surgery and reveals the variation that exists in concept regarding the role of encirclement. 


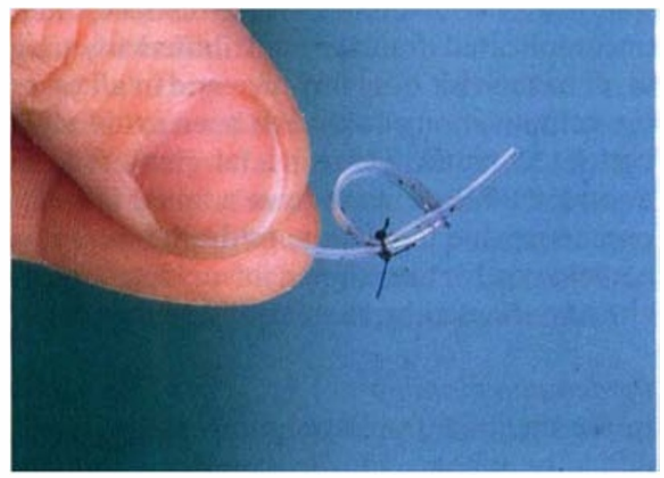

Fig. 32.

Some cases had undergone an encircling band procedure to close one or more horseshoe tears and had not been successful in doing so; this was apparently due either to the buckle being found to be too narrow and then being widened by the addition of a grooved strip of silicone creating a very shallow scleral buckle, or to an inaccurate placement of the band in the first place. Often the tears lay well anterior to the buckle, or the band lay so anteriorly that the tears came to lie behind it after further surgery; some bands were found lying over the ora. A number of cases had undergone speculative surgery when a break had not been found before operation.

Not only is there a problem of concept but also one of execution; for example the 'hourglass eye' is a not unfamiliar finding. Figures 32 and 33 illustrate a case where the diameter of the encircling band removed from an eye at reoperation was only $8 \mathrm{~mm}$ and caused considerable problems for patient and surgeon alike. The reasons for this happening are related to difficulties in controlling intraocular tension during drainage of sub-retinal fluid and tensioning the band, and perhaps there is the idea of creating a false ora serrata. ${ }^{38}$

The concept of an encircling scleral buckle originated in Boston in the $1950 \mathrm{~s}^{39}$ when it was thought that vitreous traction exerted a continuous pull on the periphery of the retina creating complex detachment problems and therefore it was necessary to have a permanent scleral buckle. ${ }^{39}$ This was achieved by reinforcing the intrascleral buckle with an encircling polyethylene tube. Not long afterwards Arruga simplified the procedure by tying a non-absorbable suture around the eye,$^{40}$ and this was then replaced by silicone rubber. ${ }^{41}$

The idea that an encircling band will solve a complex problem which is not fully understood is still quite widely held. In many cases in the 'missed tear untreated' group the primary operation had been a band which had been used in the presumed hope that it might somehow close a tear which could not be found prior to surgery.

I believe that the principle use of an encircling band is to reinforce an accurately placed silicone sponge buckle placed if possible in a radial direction after careful localisation of the tear or tears. In many eyes the state of the sclera is too poor to allow the effective suturing of a silicone sponge, and in these cases the band can be used to support the sponge for as long as it takes for the cryotherapy to develop an optimum adhesion. Many primary operations suffer early suture failure due to scleral weakness and much of this could be prevented by the support provided by an encircling band.

Where reinforcement of a circumferential buckle is required sponges are available through which an encircling band can be passed. The buckle is produced by scleral sutures over the sponge and is only supported by the encirclement.

In this series of cases of recurrent retinal detachment there were only 10 cases where

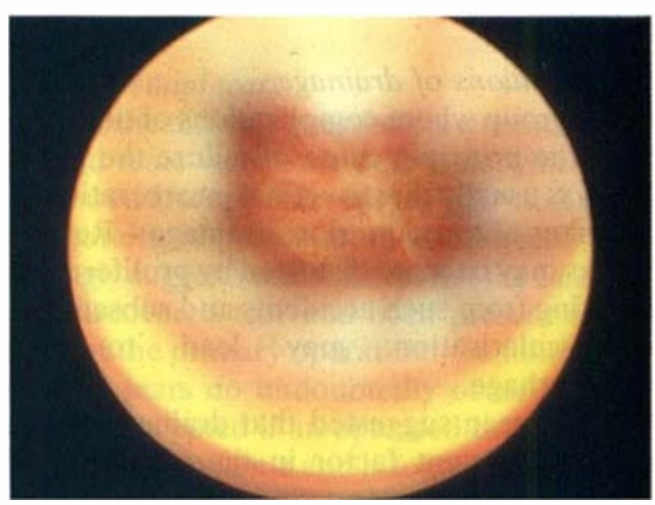

Fig. 33. 
PVR had occurred despite apparently accurate surgery where all tears had been treated, and in these the tear had been pulled off the buckle by a contracting adjacent membrane or a macular pucker. Most of these could probably not have been predicted or prevented. However in many primary detachments proliferation can be found at an early stage and the surgeon should be alert to the possible effects that this may have on retinal breaks and appropriate steps can be taken at the primary operation.

\section{Conclusions}

The purpose of the study was to clarify the position regarding the pathogenesis of proliferative vitreoretinopathy. It is not intended as a criticism of referring surgeons; the problems of recurrence for the reasons indicated are a world-wide phenomenon and relate more to the fact that retinal detachment is treated in the main by ophthalmic surgeons as part of a general surgical service and not by retinal specialists. Even in countries such as the United States where retinal detachment is treated mostly by retinal specialists a similar problem exists ${ }^{42}$ reflecting the highly complex problem presented by the treatment of many cases of retinal detachment.

The findings from this study indicate that the recurrence of a retinal detachment complicated by PVR is not primarily due to a proliferative process leading to a purely tractional redetachment. It is the failure of primary surgery to repair the causative retinal breaks which lead to recurrence which in turn leads to proliferation by perpetuating a situation whose most serious complication is PVR.

PVR is a complication of retinal detachment, it is not the result of treatment except in so far as that treatment fails to successfully relieve the underlying problem or is accompanied by avoidable surgical complication.

Some primary detachments are particularly likely to lead to PVR, especially in the case of giant tears or where other problems such as uveitis or haemorrhage have complicated the presenting problem. In these cases there is a particular need to repair the underlying pathology with an understanding of potential proliferative complications.
There is a strong argument in favour of looking for the cure of PVR in its prevention and not by seeking more and more sophistication in vitro-retinal technique. Drugs designed to inhibit proliferation may come to have a place as a preventive measure at a much earlier stage in the treatment of retinal detachment, but as a cure for established proliferative disease they are inappropriate.

Elective surgery of the vitreous has evolved rapidly over the last twenty or so years and technical developments nowadays allow us to do battle with more and more complex vitreoretinal problems. To the extent that there is a serious risk that the challenge may become paramount and we fail to look for the possibility of preventing the problem in the first place.

\section{Prevention in diabetes}

In diabetes we have long recognised the possibility of preventing the late complications of proliferative retinopathy so that it might be hoped that vitreo-retinal surgery in diabetes would be a thing of the past. There does appear to be an encouraging trend with lessening numbers of patients referred for treatment of the late complications of diabetic retinopathy. However the problem is still with us and especially in developing countries where diabetes may affect up to $10 \%$ of the population the late complications of neglected diabetic eye disease take an appalling toll of eyesight.

In the last two years I have operated on over 100 diabetic patients with late complications of diabetic retinopathy both from here and abroad. One half of the patients had received no laser treatment before their first sight losing symptom. About one third had received inadequate laser treatment where active neovascular proliferation was found at the time of vitrectomy. Only one tenth had undergone effective photocoagulation before vitrectomy.

\section{Perspectives}

In diabetes as in PVR the complications of disease are largely preventable by earlier and more careful and effective methods in primary treatment. Some primary detachment repair problems are relatively simple but many are 
difficult as a result of varying factors. Many of these are predictable and might best be repaired in specialist retinal centres where adequate time is allocated during daytime operating lists and where expertise and instincts can develop without the pressure of increasing numbers of routine procedures.

The role of the vitreo-retinal surgeon could become more retinal and less vitreal, more involved in the treatment of primary retinal problems and less in the care of terminal vitreo-retinal disease.

There are some cases where the need for vitreo-retinal surgery is possibly unavoidable, penetrating trauma involving the posterior segment continues to present serious problems and some retinal detachments become affected by PVR at a very early stage in their evolution. Some diabetics do not respond to careful and early laser photocoagulation and develop late retinal complications. However the concept of inevitability should be constantly revised by a continuing audit of our management of primary care.

\section{References}

${ }^{1}$ Straatsma BR and Allen RA: Lattice degeneration of the retina. Trans Am Acad Ophthalmol Otolaryngol 1962, 66: 600-13.

${ }^{2}$ Byer N: Lattice degeneration of the retina. Survey Ophthalmol 1979, 23: 213-48.

${ }^{3}$ Byer N: Prognosis of asymptomatic retinal breaks. Arch Ophthalmol 1974, 92: 208-10.

${ }^{4}$ Davis MD, Segal PP, McCormack A: The natural course followed by the fellow eye in patients with rhegmatogenous retinal detachment. In: Pruett RC and Regan CDJ (Eds) Retina Congress. Appleton-Century-Crofts. New York 1974, pp 643-59.

${ }^{5}$ David MD: Natural history of retinal breaks without detachment. Arch Ophthalmol 1974, 92: 183-94.

${ }^{6}$ Elliott A: Personal communication, 1989.

${ }^{7}$ Tasman WS: Posterior vitreous detachment and peripheral retinal breaks. Trans Am Acad Ophthalmol Otolaryngol 1967, 72: 217-24.

${ }^{8}$ Folk JC, Arindell EL, Klugman MR: The fellow eye of patients with phakic lattice retinal detachment. Ophthalmology 1989, 96: 72-7.

${ }^{9}$ McPherson A, O'Malley R, Beltawady SS: Management of the fellow eye of patients with rhegmatogenous retinal detachment. Ophthalmology 1981, 88: 922-34.

${ }^{10}$ Foos RY: Posterior peripheral retinal tears. Am J Ophthalmol 1974, 6: 679-87.

"Friedmann $Z$ and Neumann E: Posterior vitreous detachment after cataract extraction in non-myopic eyes and the resulting lesions. $\mathrm{Br} J$ Ophthalmol 1975, 59: 451-4.
${ }^{12}$ Okun E: Histopathology of changes which preceed retinal detachment. Mod Probl Ophthalmol 1966, 4: 76-97.

${ }^{13}$ Machemer R: Experimental retinal detachment in the owl monkey. I. Method of production and clinical picture. Am J Ophthalmol 1968, 66: 388.

${ }^{14}$ Scott JD: Congenital myopia and retinal detachment. Trans Ophthalmol Soc UK 1980, 100: 69-71.

${ }^{15}$ Francomani CA, Liberfarb R, Maumanee I, Streeten E, Meyers DA, Pyeritz RE: The Stickler syndrome: evidence for close linkage to the structural gene for type II collagen. Genomics 1987, 1: (In press.)

${ }^{16}$ Keith CG, Dobbs RH, Shaw DG, Cottrall K: Abnormal facies, myopia and short stature. Arch Dis Child 1972, 47: 787-93.

${ }^{17}$ Stickler GB, Belau PG, Farrell FJ, Jones JD, Pugh DG, Steinberg AG, Ward LE: Hereditary progressive arthro-ophthalmopathy. Mayo Clin Proc 1965, 40: 433-55.

${ }^{18}$ Daniel R, Kanski JJ, Glasspool MG: Hyaloretinopathy in the clefting syndrome. $\mathrm{Br}$ Ophthalmol 1974, 58: 96-102.

${ }^{19}$ Judisch GF, Weingart TA, Hansam JW, Montague P: Wagner's and Stickler's syndrome. Text for poster. Am Acad exhibiton 1979

${ }^{20}$ Billington BM, Leaver PK, McLeod D: Management of retinal detachment in the Wagner-Stickler syndrome. Trans Ophthalmol Soc UK 1985, 104: $875-9$.

${ }^{21}$ Percival SPB: Title. Trans Ophthalmol Soc UK 1985, 104: 915-18.

${ }^{22}$ Smith RW, Stark WJ, Maumanee E, Edgar CL, Michels RG, Glaser BM, Bonham RD: Retinal detachment after extracapsular cataract extraction with posterior chamber lens. Ophthalmology 1987, 94: 495-502.

${ }^{23}$ Ashrafzadeh MT, Schepens CL, Elzeiny II, Moura R, Morse P, Kraushar MF: Aphakic and phakic retinal detachment. Arch Ophthalmol 1973, 89: 476-83.

${ }^{24}$ Friedmann $\mathrm{Z}$ and Neumann E: Posterior vitreous detachment after cataract extraction in non-myopic eyes and the resulting lesions. $\mathrm{Br} J$ Ophthalmol 1975, 59: 451-4.

${ }^{25}$ Hyams S, Meir E, Ivry M, Krakowski D, Maythar B, Scharf J Zinger L: Israel J Med Sci 1972, 8: 1424.

${ }^{26}$ Benson WE. Gilbert Grand M, Okun E: Aphakic retinal detachment. Management of the fellow eye. Arch Ophthalmol 1973, 93: 245-9.

${ }^{27}$ Johnson SH, Kratz RP, Olson PF: Clinical experience with the Nd-Yag laser. Am Intraocular Implant Soc J 1984, 10: 452-60.

${ }^{28}$ Gardner WS, Straatsma BR, Pattit TH: Neodymium-YAG laser posterior capsulotomy: The first 100 cases at UCLA. Ophthalmic Surg 1985, 16: $24-8$.

${ }^{29}$ Keates RH, Steinert RF, Puliafito CA: Long-term follow-up of Nd-Yag laser posterior capsulotomy. Am Intraocular Implant Soc J 1984, 10: 164-8.

${ }^{30}$ Leff SR, Welch J, Tasman W: Rhegmatogenous reti- 
nal detachment after Yag laser posterior capsulotomy. Ophthalmology 1979, 94: 1222-5.

${ }^{31}$ Scott JD: Lens epithelial proliferative changes in retinal detachment. Trans Ophthalmol Soc UK 1982, 102: 385-9.

32 Duke-Elder S and Dobree JH: System of Ophthalmology 1967, Vol 10, p 822. Henry Kimpton, London.

${ }^{33}$ Benson WE, Morse PH, Nantawan P: Late complications following cryotherapy of lattice degeneration. Am J Ophthalmol 1977, 84: 514-16.

${ }^{34}$ Robertson DM and Norton EWD: Long-term follow-up of treated retinal breaks. $A m J$ Ophthalmol 1973, 75: 395-403.

${ }^{35}$ Chignell $\mathrm{AH}$ and Shilling J: Prophylaxis of retinal detachment. Br J Ophthalmol 1973, 57: 291-8.

${ }^{36}$ Robertson DM and Priluck IA: 360 degree cryretinopexy. Arch Ophthalmol 1979, 97: 2130-4.
${ }^{37}$ The Retina Society Terminology Committee. The classification of retinal detachment with proliferative vitreo-retinopathy. Ophthalmology 1983, 90: $121-25$.

${ }^{38}$ Mortada A: Choroidopathy produced by pressure on the sclera by synthetic buckling material. $\mathrm{BrJ}$ Ophthalmol 1973, 57: 274-80.

${ }^{39}$ Schepens CL: Current management of retinal detachment: Progress or chaos. 25th Gifford Memorial Lecture 1969. Chicago Ophthalmological Society.

${ }^{40}$ Arruga $\mathrm{H}$ : Technical variations in retinal surgery. Soc Oft Hisp-Am 1958, 18: 55.

${ }^{41}$ Schepens CL: Scleral buckling with circling element. $\operatorname{Tr}$ Am Acad Ophthalmol Otolaryngol 1964, 68: 959.

${ }^{42}$ Wetzig P: Personal communication 1988. 